\title{
Swell and Wind Wave Inversion Using a Single Very High Frequency (VHF) Radar
}

\author{
ZAID R. ALATTABI \\ School of the Earth, Ocean and Environment, University of South Carolina, Columbia, South Carolina, and \\ Marine Science Center, University of Basrah, Al Basrah, Iraq \\ Douglas CAHL AND GeORge Voulgaris \\ School of the Earth, Ocean and Environment, University of South Carolina, Columbia, South Carolina
}

(Manuscript received 14 September 2018, in final form 13 March 2019)

\begin{abstract}
A hybrid, empirical radar wave inversion technique that treats swell and wind waves separately is presented and evaluated using a single $48-\mathrm{MHz}$ radar unit and in situ wave measurements. This hybrid approach greatly reduces errors in radar wave inversion during swell seas. Our analysis suggests that, prior to the inversion, the second-order spectrum should be normalized using Barrick's weighting function because this process removes harmonic and corner reflection peaks from the inversion and improves the results. In addition, the resulting calibration constants for the wind wave component are not wave-frequency dependent and are similar in magnitude to those found in previous studies using different operating-frequency radars. This result suggests radar frequency independence, although additional experimental verification is required. The swell component of the model presented here ignores the effect of swell's propagation direction on the radar signal. Although this approach has several limitations and may only be useful near the coast (where swell propagates close to perpendicular to the coastline), the resulting wave inversion is accurate even when swell is propagating close to perpendicular to the radar beam direction. RMS differences relative to in situ wave height measurements range from 0.16 to $0.25 \mathrm{~m}$ as the radar beam angle increases from $22^{\circ}$ to $56^{\circ}$.
\end{abstract}

\section{Introduction}

Sea state information is usually collected using in situ sensors that record local wave conditions. Determination of spatial variability requires the deployment of several sensors making it a difficult and costly activity. Satellite technologies (i.e., Jackson 1981; Guymer 1990) have been used for wave height estimations over large scales, but their application is challenging because of temporal resolution (based on satellite orbit and repetition coverage rate). Although recent advances in satellite technology and signal analysis (i.e., Collard et al.2005) have made applications in the coastal ocean feasible, their application is still constrained by their spatial resolution $(\sim 2.5 \mathrm{~km})$ that makes them comparable to those of low-frequency radars. This part of the coastal ocean, extending from the coastline to a range of tens to hundreds of kilometers offshore, is the area that mid- to high-frequency $(\mathrm{HF})$ radars can provide

Corresponding author: George Voulgaris, gvoulgaris@geol.sc.edu both surface current and wave data, at high spatial and temporal resolution allowing identification of spatial gradients. The HF radar-derived parameters can facilitate operational activities that can utilize the data as either stand-alone information or integrated with numerical models through data assimilation (e.g., Paduan and Shulman 2004; Waters et al. 2013).

The HF radar signal backscattered from the ocean surface is used to calculate the radar's Doppler energy spectrum (Crombie 1955; see Fig. 1) at a number of locations over the radar coverage area. The two largest and narrowest (first order) peaks in the Doppler spectrum are the result of backscatter by ocean waves with a wavelength half the radar's wavelength. The shift from the theoretical Bragg frequency, defined by the operating frequency of the HF radar, is used to estimate the ocean surface current along the direction of the radial beam (radial currents; e.g., Paduan and Rosenfeld 1996). The spectral continuum (second-order scattering), present on either side of each first-order Bragg peak, contains information on ocean waves at frequencies 


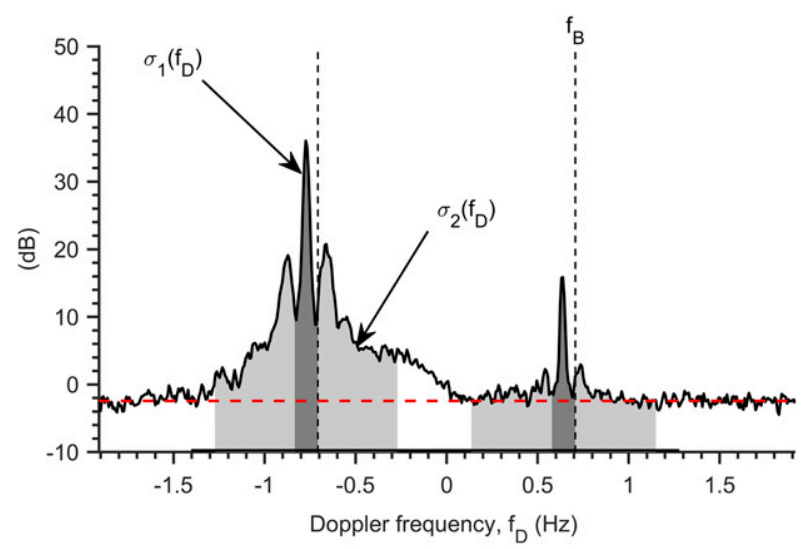

FIG. 1. Example of HF radar Doppler backscatter spectrum showing the first- $\left[\sigma_{1}\left(f_{D}\right)\right.$; dark gray $]$ and second-order $\left[\sigma_{2}\left(f_{D}\right)\right.$; light gray] continuum regions of the spectrum. The vertical dashed lines indicate the theoretical Bragg frequency and correspond to the frequency at which the first-order peaks should be appearing in the absence of surface currents. The horizontal dashed red line refers to the noise level. Data shown are from the 48-MHz, 12-antenna beamforming radar system used in this study.

other than that of the Bragg frequency. These areas are the result of nonlinear interactions between the electromagnetic (EM) and ocean surface waves that satisfy the requirement that the sum of the wavenumber vectors equals that of the Bragg wave (i.e., Stewart 1971; Hasselmann 1971; Weber and Barrick 1977).

Barrick (1971) and Barrick and Weber (1977) used nonlinear integral equations to develop the theoretical approach that describes the relationship between ocean waves and HF radar Doppler spectra. Subsequently, a number of theoretical inversion methods were developed for the inversion of the nonlinear integral equations and the extraction of ocean wave spectra from HF radar Doppler spectra. Barrick (1977b) presented the first inversion method; this was improved by Lipa (1977) who linearized Barrick's equations and used a theoretical wave spectrum and a stabilization technique to carry out the inversion. Gill (1990) and Howell and Walsh (1993) developed a method for the inverse analysis that uses singular value decomposition techniques to solve the linearized equations. This method was later extended by Zhang and Gill (2006) for bistatic radar systems. Wyatt (1990) applied the Chahine-Twomey relaxation method to invert the nonlinear integral equation of radar cross section. Although this solution is limited to wave frequencies of less than $0.2 \mathrm{~Hz}$, it was argued that it is capable of providing a good estimation of the directional wave spectrum. A nonlinear optimization algorithm that does not require any linearization or approximation was presented by Hisaki (1996) to solve the nonlinear integral equations.
In addition to the complex and computationally intensive methods described above, other simpler, mostly empirical methods have been developed. Barrick (1977a) was the first to derive an approximation for calculating nondirectional wave spectra and bulk parameters as wave height and period. Barrick (1977b) tested his empirical method against wave buoy data and later on, Maresca and Georges (1980) and Heron et al. (1985) developed modified versions of Barrick's method. Heron and Heron (1998) compared these parameterized inversion methods against in situ data and concluded that Barrick's (1977b) original method performed the best.

Gurgel et al. (2006) extended the empirical algorithm to allow the estimation of wave directional characteristics using two phased-array HF radars that look on the same patch of the ocean from different directions. Although this method requires two radar systems, its accuracy depends on the performance of each individual unit and the accuracy of the coefficients (see section 2) used for the inversion of the signal from each unit. More recently, Lopez et al. (2016) evaluated the method of Gurgel et al. (2006) using data from a pair of $12-\mathrm{MHz}$ phased-array HF radars deployed over a period of 5 months. Their calibration resulted in coefficients different than those suggested by Gurgel et al. (2006) even after accounting for the difference in operating frequency. The authors of that study suggested that discrepancies in the estimations could be due to antenna sidelobes, the presence of second-harmonic peaks in the Doppler spectrum, and the presence of swell waves. Although, Barrick (1977a) has suggested that weighting of the normalized second-order spectra by the appropriate coupling coefficient helps eliminating the harmonic peaks, this was not utilized in either Lopez et al. (2016) or Gurgel et al. (2006). Furthermore, the empirical method was applied across all wave frequency bands, although Lipa and Barrick (1980) and Forget et al. (1981) had noted that the parameterized inversion technique does not apply to swell.

Most of the work reported in the literature is based on the use of common radar systems operating at high frequencies ranging from 4 to $30 \mathrm{MHz}$. These systems provide spatial resolutions ranging between 0.3 and $5 \mathrm{~km}$, and their range varies from 20 to $200 \mathrm{~km}$ (Paduan and Washburn 2013). On the other hand, very high frequency (VHF) systems $(30-50 \mathrm{MHz})$ can achieve higher spatial resolutions of $150-300 \mathrm{~m}$ but with a lower range of 10-15 km (Broche et al. 1987; Shay et al. 2002; Molcard et al. 2009; Shrira et al. 2001; Voulgaris et al. 2011). Although the accuracy of those systems in measuring surface currents is similar to that of lower-frequency systems (Voulgaris et al.2011), their ability to measure waves has not been examined before. 
In this study, we examine the applicability of the empirical inversion method for the estimation of ocean wave spectra and bulk wave parameters [i.e., root-mean-square (RMS) wave height, peak wave period, mean wave period, wind and wave direction] using a single VHF $(48 \mathrm{MHz})$ system. Single site performance controls the accuracy of estimations, when two or more overlapping radars are used, and they can increase the coverage area for wave extraction, in areas of no station coverage overlap (Wyatt 2002). Contrary to previous studies using empirical methods, in here, we attempt to increase the accuracy of the method by accounting for the presence of swell waves through the development of a hybrid technique. The new technique is applied on VHF radar Doppler spectra and the results are compared against ocean wave spectra obtained using in situ instrumentation deployed over a variety of ranges and beam angles in relation to the VHF radar unit. In the following, section 2 outlines the hybrid empirical inversion method used for the extraction of wave spectra from the VHF radar signal. Subsequently, in section 3, the experimental setup and data collection are presented. The results of both the calibration and inversion using the model are presented in section 4 . In section 5, the findings from the application of the model are discussed while the conclusions of this study are presented in section 6 .

\section{Wave inversion model}

Locally generated wind waves exhibit large directional spreading and individual waves of different wavelengths and directions interact with each other and the radar signal, contributing to the backscattered radar signal (Barrick and Weber 1977; Lipa 1978). The accuracy of radar wave inversion has found to be related to the magnitude between the radial beam direction and wave propagation direction (Barrick 1977b). It has been shown that when wave direction is near perpendicular to the beam direction, the accuracy of wave estimates is reduced. On the other hand, swell waves have very narrow (singular) directional characteristics that violate the assumptions made regarding the contribution of waves in the Doppler spectrum. This has led to the development of specialized methods for inversion for swell waves (Lipa and Barrick 1980; Lipa et al. 1981). The presence of swell was used to explain the discrepancies found between observations and estimates using the wind wave inversion method (Lopez et al. 2016). In their study, Lopez et al. (2016) found different regression coefficients for different cross angles (the angle between wave direction and radar beam direction) and this can be attributed to the presence of sharply peaked (in both frequency and direction) swell waves. Recognizing these differences, we present a model that combines the methods presented by Heron and Heron (1998) and Lipa et al. (1981) into single hybrid empirical model. Its application requires defining the frequency $f_{c}$ that separates wind from swell waves. This could be achieved using the wave age criterion (Hanson and Phillips 2001), but it requires information on wind speed and direction. In practical applications, if no wind information is available, the value of this frequency can be determined using historic records or wave climate analysis. Along the coast of the southeastern United States, $0.1 \mathrm{~Hz}$ can be used as the separation frequency while a lower value will be applicable for the west coast where swells are more prominent (Kumar et al. 2013).

\section{a. Module for wind driven seas}

Barrick's (1977b) model has been the basis for the development of most empirical methods to date for the extraction of wave characteristics from second-order Doppler spectra. It is based on a simple relationship between ocean wave height and the weighted secondorder sidebands, normalized by the total first-order energy of the Doppler spectrum, denoted as $R_{W}$. Following Heron and Heron (1998), the bulk RMS wave height, defined as $H_{\mathrm{rms}}=\left(8 m_{0}\right)^{1 / 2}(\mathrm{WMO} 1998)$, where $m_{0}$ is the 0 th moment of sea surface variance, can be estimated as

$$
H_{\mathrm{rms}}=\xi\left(4 / k_{0}\right) R_{W}^{1 / 2},
$$

where $k_{0}$ is the radar wavenumber and $\xi$ is an empirical constant. Note that in Barrick (1977b) and other HF radar studies (i.e., Heron and Heron 1998; Ramos et al. 2009) RMS wave height was defined as simply the standard deviation of the sea surface variability. In this manuscript we have adopted the WMO (1998) definition, as to be consistent with common practices of wave measurements.

Following Heron and Heron (1998), the noise level for each individual Doppler spectrum is first identified, using the method described in Hildebrand and Sekhon (1974), and removed from the recorded spectrum. Then $R_{W}(f)$ is estimated from each side (i.e., negative and positive frequency ranges) of the Doppler spectrum. Most studies exclude the side with the lower signal-to-noise ratio (SNR); however, if SNR is similar, including both sides (i.e., averaging) can improve the wave inversion. Since $H_{\mathrm{rms}}$ is derived from the integral of the wave energy spectrum, Eq. (1) can be expanded to its equivalent spectral form so that the wind wave energy spectrum $S_{w}(f)$ is given by 


$$
S_{w}(f)=\alpha(f) \frac{2 R_{W}(f)}{k_{0}^{2}},
$$

where $\alpha(f)$ is a calibration coefficient that depends on wave frequency $f$, as in Gurgel et al. (2006). Contrary to Gurgel et al. (2006) and Lopez et al. (2016), $R_{W}$ here is the "weighted" second-order continuum normalized by the integrated first-order spectra; it was defined by Barrick (1977a,b) as a function of the radar-derived Doppler frequency $f_{D}$ as

$$
R_{W}\left(f_{D}\right)=\frac{\sigma_{2}\left(f_{D}\right) / W\left(f_{D} / f_{B}\right)}{\int_{f_{B}-\Delta f}^{f_{B}+\Delta f} \sigma_{1}\left(f_{D}\right) d f_{D}},
$$

where $\sigma_{1}$ and $\sigma_{2}$ are the first and second-order spectra, $\Delta f$ is the small frequency band around the first-order Bragg peak $f_{B}$ corresponding to the peak half-width, and $W$ is the weighting function defined in Barrick (1977b, see Fig. 3 therein) for deep water conditions. Ocean wave $(f)$ and radar Doppler $\left(f_{D}\right)$ frequencies are related through the radar Bragg frequency $\left(f_{B}\right)$; the latter corresponds to zero ocean wave frequency, so that $f=\left|f_{D}-f_{B}\right|$.

\section{b. Module for swell}

Swell consists of gravity waves propagating outside their area of generation and are not in equilibrium with the local wind conditions (Hanson and Phillips 2001); they are sharply peaked in both frequency and direction, and as shown in Maresca and Georges (1980), Lipa and Barrick (1980), and Bathgate et al. (2006) require a separate radar inversion method. In these narrow beam radar models, swell waves appear as peaks in the second-order sidebands of the radar Doppler spectrum and they are located close to the first-order peak. Their amplitude is proportional to $\cos ^{2} \theta_{s}$, where $\theta_{s}$ is the angle between the radar beam and the swell propagation direction [for details see Lipa and Barrick (1980) and Bathgate et al. (2006)]. When swell waves cross the radar beam within $\pm 30^{\circ}$ from perpendicular large inaccuracies in the swell inversion are reported (Bathgate et al. 2006; Wang et al. 2016). However, in nearshore applications refraction due to the shallow water depths causes swell waves to approach the coastline at very small angles, almost perpendicular to the coastline (but not necessarily perpendicular to the radar beam direction). The roughly constant propagation direction of swell waves near the coastline allows us to assume limited directional effects in the nearshore and propose a simpler model.

Equation (3) with $W\left(f_{D} / f_{B}\right)=1$ is used to estimate the radar swell cross section ratio in the swell band; its peak value $R_{s}$ is used to estimate the RMS wave height of swell $H_{s}$ as

$$
H_{s}^{2}=\alpha_{s} \frac{2 R_{s}}{k_{0}^{2}}
$$

where $\alpha_{s}$ is an empirical factor that accounts for directional characteristics and other system dependent variabilities similarly to the empirical factor in Eq. (2) for wind waves. In addition, this factor includes the effect of the coupling coefficient, which for swell is different than it is for wind waves (Lipa et al. 1981). The RMS swell wave height $H_{s}$ can be converted to an energy spectrum using a Gaussian function that distributes the swell energy over the swell frequency band with the peak energy centered at the swell peak frequency $f_{s}$ :

$$
S_{s}(f)=\left(H_{s}^{2} / 8 \sqrt{2 \pi \sigma^{2}}\right) e^{-\left(f-f_{s}\right)^{2} / 2 \sigma^{2}},
$$

where $\sigma$ represents the width of the spectra, which can be determined from existing in situ wave spectra from the study area or using validated model hindcasting results (e.g., Kumar et al. 2017).

Following Lipa et al. (1981), the swell peak frequency $f_{s}$ is determined from the four swell peaks in the Doppler spectrum (defined from lowest to highest in Doppler frequency as $f_{1}^{-}, f_{2}^{-}, f_{3}^{+}$, and $f_{4}^{+}$, with the superscripts defining the sign of the side of the Doppler spectrum). There are used to estimate swell frequency as $f_{s}=$ $\left(\Delta f^{+}+\Delta f^{-}\right) / 4$, or $f_{s}=\Delta f^{+ \text {or- }} / 2$, depending on whether one or both sides of the Doppler spectrum are used, where $\Delta f^{-}=f_{1}^{-}-f_{2}^{-}$and $\Delta f^{+}=f_{4}^{+}-f_{3}^{+}$.

The swell and the wind wave spectra can be combined into a single wave energy density spectrum $\left[S(f)=S_{w}(f)+S_{s}(f)\right]$.

\section{c. Wind and wave direction}

Given the high frequency of the ocean Bragg waves, it is assumed that they are aligned with the local, wavegenerating wind. Thus, wind direction can be estimated using (Long and Trizna 1973; Fernandez et al. 1997)

$$
\zeta=\sigma_{1}\left(f_{D}^{+}\right) / \sigma_{1}\left(f_{D}^{-}\right)
$$

where $\sigma_{1}\left(f_{D}^{+}\right)$and $\sigma_{1}\left(f_{D}^{-}\right)$represent the first-order Bragg peak energies (i.e., the integral of the first-order region of the spectra) corresponding to approaching and receding ocean Bragg waves, respectively. A directional distribution function $G(\theta)$ of the Bragg ocean waves is used to relate the ratio $\zeta$ to the direction of ocean waves (Longuet-Higgins 1963):

$$
G(\theta)=A \cos ^{s}(\theta / 2)
$$


where $s$ is the spreading factor, $A$ is a constant that satisfies $\int_{-\pi}^{+\pi} G(\theta) d \theta=1$, and $\theta=\theta_{r}-\theta_{w}$, with $\theta_{w}$ representing Bragg wave (wind) direction and $\theta_{r}$ representing the radar beam direction. Substituting Eq. (6) in Eq. (7) and after some manipulation, the Bragg wave (wind) direction is estimated as

$$
\theta_{w}=\theta_{r} \pm 2 \arctan \left(\zeta^{1 / s}\right)
$$

The plus/minus sign refers to directional ambiguity for a single radar system. Parameter $s=2$ is commonly used as it allows simplicity in the calculation when two systems are used (Gurgel et al. 2006; Fernandez et al. 1997). The ambiguity issue can be resolved using two or more radar systems that look at the same ocean area from different angles, or when the directional characteristics of the Bragg wave/wind are well constrained by the environmental setting (i.e., coastline morphology) or through other means.

Gurgel et al. (2006) expanded the method described above for the calculation of Bragg wave/ wind direction to the second-order Doppler sideband energies. They utilized the $f$-dependent ratio of the second-order side band corresponding to receding waves $\left[\sigma_{2}^{-}(f)\right]$ over the side corresponding to approaching waves $\left[\sigma_{2}^{+}(f)\right]$ to define the direction of ocean waves with frequency $f$ as

$$
\theta(f)_{\mathrm{inv}}=\theta_{r} \pm 2 \arctan \left\{\left[\frac{\sigma_{2}^{+}(f)}{\sigma_{2}^{-}(f)}\right]^{1 / s}\right\},
$$

where $\theta_{r}$ is radial beam direction, and $s$ is the wave directional spreading factor as in Eq. (8). As for the case of wind direction, the ambiguity in the solution of Eq. (9) can be resolved using multiple radar stations or by utilizing additional information.

\section{In situ and VHF radar data availability and analysis}

The data used in this study were collected as part of an experiment carried out in the vicinity of Diamond Shoals, a sand shoal complex that extends up to $40 \mathrm{~km}$ offshore from Cape Hatteras Point, North Carolina. The experiment was carried out under the auspices of the Carolinas Coastal Change project, led by the U.S. Geological Survey, and details can be found in Armstrong et al. (2013). A number of in situ acoustic current profilers were deployed in the surf-zone and inner shelf regions of the study area (Fig. 2). In addition, a single VHF radar station with a coverage area that included the in situ data collection sites was operated during the experimental period.

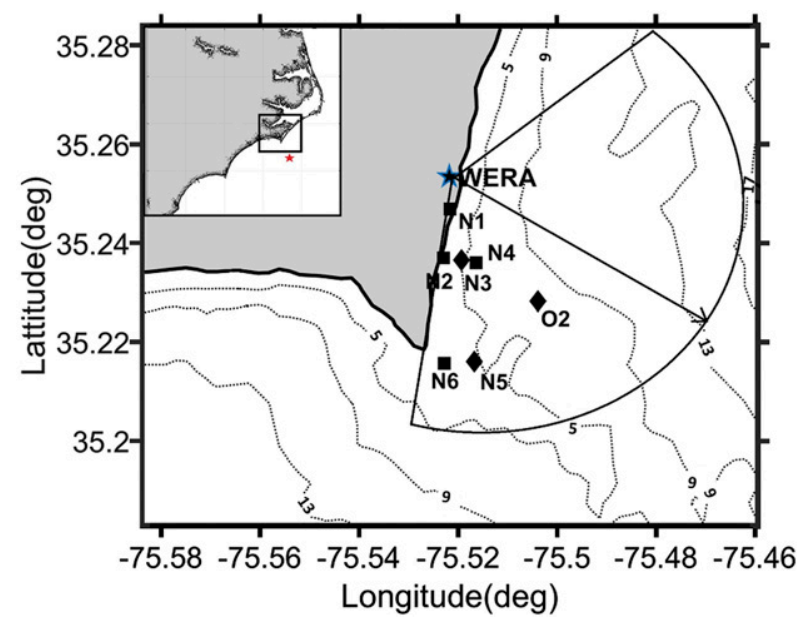

FIG. 2. Experimental site location map showing the bathymetry around Cape Hatteras (bathymetry data are from https:// www.ngdc.noaa.gov/mgg/bathymetry/relief.html), radar coverage area, and the locations of in situ stations and Diamond Shoals buoy 41025 (red star in insert). The radar boresight direction $\left(0^{\circ}\right.$ beam angle $)$ is indicated by the arrow vector.

\section{a. In situ data}

Wave and current data were collected at 13 locations dispersed throughout the study area (see Kumar et al. 2013; List et al. 2011). Only seven of these sites (O2, $\mathrm{N} 1, \mathrm{~N} 2, \mathrm{~N} 3, \mathrm{~N} 4, \mathrm{~N} 5$, and N6) were within the footprint of the radar coverage area (see Table 1 and Fig. 2). Site $\mathrm{O} 2$ was located at a water depth of $10.7 \mathrm{~m}$ and provided hourly measurements. Four of the sites $(\mathrm{N} 1, \mathrm{~N} 2, \mathrm{~N} 3$, and N4) were located to the east of the cape and its associated shoal, while the remaining two (N5 and N6) were deployed over the shoal itself. The instrumentation consisted of Nortek AS Aquadopp (AQD) and Teledyne RD Instruments acoustic Doppler current profilers (ADCP) measuring threedimensional flow velocities (bin size of $40 \mathrm{~cm}$ ) and pressure fluctuations with a sampling frequency of $1 \mathrm{~Hz}$. The AQD sensors (sites N1, N2, N3, and N6) were set up to collect data continuously while the ADCPs (sites O2, N4, and N5) were collecting data in burst mode (1024 data points, every hour, centered on the hour). The continuous AQD records were divided into 1024-s-long segments, centered on the hour, to match the ADCP and VHF data collection. The types of instrumentation deployed at each site, their period of data collection, and their depths are listed in Table 1. Pressure $p$ and horizontal $(u, v)$ velocity records corresponding to the bin closer to the bed $[0.40$ meters above bed (mab) for the ADP sites, $0.64 \mathrm{mab}$ for the $\mathrm{O} 2$ and N5 ADCPs, and 1.60 mab for N4 ADCP] were used to calculate power spectral and cross-spectral densities using Welch's (1967) method (15 ensembles of 128 data 
TABLE 1. Details of instrument types, water depth, data availability, range of the site from the VHF radar, angle of the radar beam to each site from the radar boresight, and mean SNR for the first- and second-order peaks extracted from the radar Doppler spectra.

\begin{tabular}{|c|c|c|c|c|c|c|c|}
\hline Site & $\begin{array}{l}\text { Instrument } \\
\text { type }\end{array}$ & $\begin{array}{l}\text { Depth } \\
(\mathrm{m})\end{array}$ & $\begin{array}{l}\text { Deployment period } \\
\text { (2010) }\end{array}$ & $\begin{array}{l}\text { Range } \\
(\mathrm{km})\end{array}$ & $\begin{array}{c}\text { Beam angle } \\
\left({ }^{\circ}\right)\end{array}$ & $\begin{array}{l}\text { First-order mean } \\
\quad \text { SNR }(\mathrm{dB})\end{array}$ & $\begin{array}{l}\text { Second-order mean } \\
\text { SNR }(\mathrm{dB})\end{array}$ \\
\hline N1 & AQD & 4.7 & 9-22 Feb & 0.7 & 51.9 & 41.2 & 27.4 \\
\hline $\mathrm{N} 2$ & AQD & 7.0 & 11-21 Feb & 1.8 & 55.8 & 39.6 & 24.0 \\
\hline N3 & AQD & 6.0 & 9-22 Feb & 1.9 & 45.8 & 41.3 & 24.9 \\
\hline N4 & ADCP & 8.8 & 9-22 Feb & 2.0 & 38.2 & 41.6 & 25.2 \\
\hline N5 & $\mathrm{ADCP}$ & 6.1 & 2-21 Feb & 4.2 & 46.1 & 28.1 & 17.5 \\
\hline N6 & AQD & 4.7 & 2-21 Feb & 4.2 & 53.5 & 26.0 & 17.7 \\
\hline $\mathrm{O} 2$ & $\mathrm{ADCP}$ & 10.7 & 4 Feb-20 Mar & 3.3 & 22.3 & 39.8 & 26.5 \\
\hline
\end{tabular}

points each, with $50 \%$ overlap). The sea surface power spectral density was estimated from the pressure spectra after correcting for pressure attenuation with depth (Bishop and Donelan 1987). To reduce amplification of noise, the analysis was performed to a maximum frequency of $0.25 \mathrm{~Hz}$ (except for site $\mathrm{O} 2$, where the maximum frequency was set to $0.195 \mathrm{~Hz}$ because of the larger water depth). The surface spectra and corresponding cross-spectral densities were used to calculate wave height, period, direction, and directional spreading using the moments method (Herbers et al. 1999). Partitioning of the wave field (energy and direction) into swell and wind waves was carried out by integrating the wave spectra over the frequency bands below and above $0.1 \mathrm{~Hz}$, respectively.

Meteorological data and offshore wave conditions for the deployment period were obtained from the NOAA/ National Data Buoy Center (NDBC) Diamond Shoals buoy (41025; Fig. 2) which is located some $29 \mathrm{~km}$ from the VHF radar station and at a mean water depth of $48 \mathrm{~m}$.

\section{b. VHF radar data}

A single, 12-antenna, phased-array, VHF Wellen Radar (WERA) system (Gurgel et al. 1999), manufactured by Helzel Messtechnick $\mathrm{GmbH}$, was deployed at the study site (Fig. 2). Its operational frequency was $48 \mathrm{MHz}$, and the use of $1-\mathrm{MHz}$ bandwidth during transmission resulted in $150-\mathrm{m}$ range resolution. Radar data were obtained 2 times per hour for the period 3-26 February 2010 with continuous radio transmission for a period of $14.8 \mathrm{~min}$ centered on 0 and $30 \mathrm{~min}$ past the hour. A total of 967 transmissions were made over the 22-day data collection period, with limited interruptions resulting from main power issues $(95 \%$ data recovery rate). For this analysis Doppler spectra were estimated by steering the beam of the VHF radar system at the instrument locations at the appropriate range cell. The Doppler spectra have a frequency resolution of $0.009 \mathrm{~Hz}$ and cover the range from -2.29 to $2.29 \mathrm{~Hz}$ (the Nyquist frequency of a $4.48-\mathrm{Hz}$ chirp rate). The energy is expressed in decibels defined using an arbitrary reference level, as recorded internally by the WERA system. Radial surface velocity estimates from the Doppler spectra were compared with the point measurements obtained using the in situ instrumentation and they found to agree with an error ranging between 4 and $12 \mathrm{~cm} \mathrm{~s}^{-1}$ (Voulgaris et al. 2011), although these findings are not presented here.

For this analysis, only Doppler spectra that coincide with the times of wave data collection using the in situ sensors (hourly for O2, N4, and N5, and half-hourly for $\mathrm{N} 1, \mathrm{~N} 2, \mathrm{~N} 3$, and N6) are used. The range to the in situ sensor locations from the radar receive $(\mathrm{Rx})$ antenna array, as well as the angle between the beam-forming direction and the radar boresight, is listed in Table 1. Site N1 was the closest to the radar $(0.7 \mathrm{~km})$, and the largest range $(4.2 \mathrm{~km})$ corresponds to sites N5 and N6. The site with a radial beam direction closest to the radar boresight was $\mathrm{O} 2\left(22.3^{\circ}\right)$, and site N6 was the one with the largest beam angle $\left(53.5^{\circ}\right)$.

We use sites $\mathrm{N} 4$ and $\mathrm{O} 2$ (Fig. 2) to calibrate the model presented in section 2 and to estimate the empirical coefficients for the wind wave and swell components of the model. The second-order sidebands are limited to a low frequency of $0.058 \mathrm{~Hz}$ (lower frequencies are often contaminated by first-order noise) and an upper limit of $0.5 \mathrm{~Hz}$ (values above this were often close to the noise of the HF radar signal), which covers wave periods from 2 to $17 \mathrm{~s}$.

The inversion is carried out using only the dominant side of the Doppler spectrum unless the two Bragg peaks differ by less than $3 \mathrm{~dB}$. In the latter case an average of both sides is used. The swell peak frequencies $\left(f_{1}^{-}, f_{2}^{-}, f_{3}^{+}\right.$and $\left.f_{4}^{+}\right)$are estimated using the weighted mean method of Young (1995) with $n=5$ (Young and Verhagen 1996):

$$
f_{m}=\frac{\sum \sigma_{2 m}\left(f_{i}\right)^{n} f_{i}}{\sum \sigma_{2 m}\left(f_{i}\right)^{n}}, \text { where } f_{i}<f_{c},
$$

here $m=1, \ldots, 4$ denotes the four sidebands from lowest to higher frequency and $i$ is the index of the discrete frequency at which a Doppler estimate is available. 


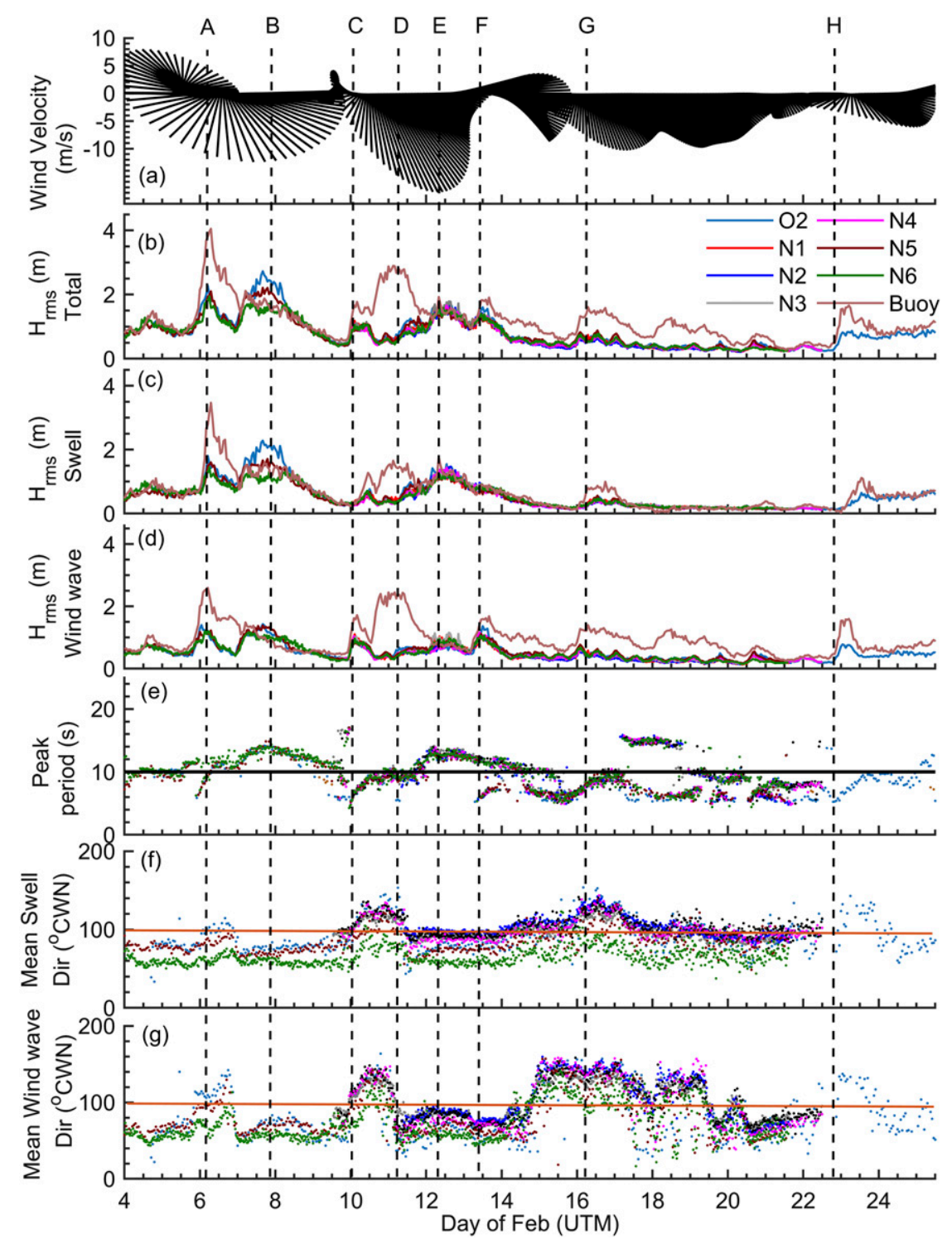

FIG. 3. Time series of offshore winds (NOAA buoy station 41025) and bulk wave parameters measured offshore at the buoy and instrumented sites (see Fig. 2): (a) wind vector diagram, (b) total RMS wave height for all sites, partitioned (c) swell and (d) gravity wave heights, (e) peak wave period (the horizontal line at $10 \mathrm{~s}$ shows the separation between swell and wind waves), and mean wave direction (from true north) for (f) swell and (g) wind waves. Horizontal lines in (f) and (g) denote the direction perpendicular to the local coastline direction. Vertical lines marked A-H identify specific wind waves/swell events (see text for details).

\section{Results}

\section{a. Wind and wave conditions}

Time series of wind conditions recorded offshore, at the NDBC buoy location, and wave conditions recorded both offshore at the buoy location and in the nearshore, within the HF radar coverage domain are shown in Fig. 3. A number of wind events are identified, with the largest one commencing on 6 February and lasting until
10 February. During this event, only sites O2, N5, and N6 were operational (see Table 1) and waves reached offshore wave height of approximately $4 \mathrm{~m}$ (see Fig. 3b, day 6). In the nearshore, during the initial period (days 6-6.4), wave energy in the wind wave band was dominant; after day 6.4, swell waves became dominant. Times representing these two conditions are marked on Fig. 3 as A (day 6.21) and B (day 7.96), respectively. On 10 February, a second frontal system moved in the area 
TABLE 2. Summary of bulk total and partitioned (swell/wind wave) wave conditions (i.e., RMS wave height, frequency, and direction) at sites $\mathrm{O} 2$ and $\mathrm{N} 4$ for each of the events (A-H) shown in Fig. 3. The corresponding VHF radar Doppler spectra characteristics are also listed.

\begin{tabular}{|c|c|c|c|c|c|c|c|c|}
\hline & A & B & $\mathrm{C}$ & $\mathrm{D}$ & $\mathrm{E}$ & $\mathrm{F}$ & $\mathrm{G}$ & $\mathrm{H}$ \\
\hline & \multicolumn{8}{|c|}{ Site O2 } \\
\hline Time (day) & 6.20 & 8.00 & 10.10 & 11.54 & 12.54 & 13.7 & 16.54 & 23.16 \\
\hline Total $H_{\mathrm{rms}}(\mathrm{m})$ & 2.30 & 2.00 & 1.10 & 1.20 & 1.70 & 1.30 & 0.70 & 0.80 \\
\hline Swell $H_{\mathrm{rms}}(\mathrm{m})$ & 1.10 & 2.00 & 0.20 & 0.50 & 1.40 & 0.60 & 0.20 & 0.20 \\
\hline Wind $H_{\mathrm{rms}}(\mathrm{m})$ & 2.00 & 1.30 & 1.10 & 1.00 & 0.90 & 1.20 & 0.70 & 0.80 \\
\hline Peak frequency $f_{P}(\mathrm{~Hz})$ & 0.10 & 0.07 & 0.15 & 0.10 & 0.08 & 0.14 & 0.12 & 0.13 \\
\hline Mean frequency $f_{m}(\mathrm{~Hz})$ & 0.10 & 0.09 & 0.15 & 0.12 & 0.09 & 0.13 & 0.13 & 0.14 \\
\hline Mean swell direction $\left({ }^{\circ}\right)$ & 99.0 & 74.6 & 102.6 & 46.0 & 87.0 & 76.0 & 152.5 & 120.0 \\
\hline Swell cross direction $\left({ }^{\circ}\right)$ & 50.6 & 75.5 & - & 76.0 & 63.0 & - & - & - \\
\hline Mean wind wave direction $\left(^{\circ}\right)$ & 109.0 & 76.8 & 109.7 & 54.0 & 74.0 & 54.0 & 140.0 & 130.0 \\
\hline Wind wave cross direction $\left(^{\circ}\right)$ & 40.0 & 73.0 & 40.00 & 84.0 & 75.0 & 84.0 & 10.0 & 19.0 \\
\hline Noise (dB) & -1.00 & -0.50 & -6.20 & -1.04 & 1.22 & -0.60 & 1.74 & -1.08 \\
\hline \multirow[t]{2}{*}{$\left(\sigma_{1} / \sigma_{2}\right)_{\text {peak }}(\mathrm{dB})$} & 1.30 & 1.60 & 6.00 & 8.00 & 2.90 & 6.30 & 9.60 & 75.00 \\
\hline & \multicolumn{8}{|c|}{ Site N4 } \\
\hline Time (day) & 6.21 & 7.96 & 10.08 & 11.54 & 12.54 & 13.67 & 16.54 & 23.16 \\
\hline Total $H_{\mathrm{rms}}(\mathrm{m})$ & - & - & 1.10 & 0.96 & 1.70 & 1.20 & 0.70 & - \\
\hline Swell $H_{\mathrm{rms}}(\mathrm{m})$ & - & - & 0.20 & 0.4 & 1.00 & 0.60 & 0.20 & - \\
\hline Wind $H_{\text {rms }}(\mathrm{m})$ & - & - & 1.00 & 0.85 & 0.98 & 1.00 & 0.70 & - \\
\hline Peak frequency $f_{P}(\mathrm{~Hz})$ & - & - & 0.14 & 0.1 & 0.07 & 0.14 & 0.12 & - \\
\hline Mean frequency $f_{m}(\mathrm{~Hz})$ & - & - & 0.16 & 0.12 & 0.10 & 0.13 & 0.14 & - \\
\hline Mean swell direction $\left({ }^{\circ}\right)$ & - & - & 100 & 73 & 85 & 86 & 138 & - \\
\hline Swell cross direction $\left({ }^{\circ}\right)$ & - & - & - & 87 & 79 & - & - & - \\
\hline Mean wind wave direction $\left({ }^{\circ}\right)$ & - & - & 114.0 & 70.0 & 78.0 & 71.0 & 151.0 & - \\
\hline Wind wave cross direction $\left({ }^{\circ}\right)$ & - & - & 51.0 & 84.0 & 87.0 & 85.0 & 14.0 & - \\
\hline Noise $(\mathrm{dB})$ & - & - & -2.25 & 5.50 & 3.90 & 3.70 & 8.00 & - \\
\hline$\left(\sigma_{1} / \sigma_{2}\right)_{\text {peak }}(\mathrm{dB})$ & - & - & 12.20 & 9.20 & 4.00 & 13.80 & 6.10 & - \\
\hline
\end{tabular}

that produced elevated sea state (up to $3 \mathrm{~m}$ RMS wave height on 11 February) for a period of a few days. During this event, all sites, except for N2, were operational (see Table 1). In Fig. 3, D denotes the time when high wind waves are present offshore (day 11.54), while E identifies the time when swell waves were recorded both offshore and in the nearshore (day 12.54). We highlight a few more wind events on days 10.08, 13.66, 16.54, and 23.1 when $H_{\text {rms }}$ values varied between 0.5 and $1 \mathrm{~m}$ (see C, F, G and H in Fig. 3). These represent wave conditions with different directions and peak frequencies (see Table 2). Although no directional wave information exists offshore, the wind data from the NDBC buoy indicate an alongshore windgenerated wave propagation predominantly from North. In the nearshore, mean wave directions, for both wind and swell waves, are within 20 degrees from perpendicular to the coastline (see Fig. 3g).

\section{b. In situ wave spectra}

The full wave spectra $S(f)$, from sites $\mathrm{O} 2$ and N4, used to estimate the wave parameters are shown in Fig. 4. The same spectra were used to estimate the coefficients for the wave inversion model presented in section 2 [see Eqs. (2) and (5)]. Spectra covering the whole VHF radar deployment period are available for site $\mathrm{O} 2$ (see Fig. 4), while N4 was deployed on 9 February and after the occurrence of the first significant wind event. The individual events/conditions (A-H) identified in Fig. 3 are also shown in Fig. 4.

\section{c. VHF radar Doppler spectra}

The radar-derived Doppler spectra for sites N4 and $\mathrm{O} 2$, for the full deployment period, are shown in Fig. 5 in the form of a time stack. The highest values at each time step present in the positive and negative Doppler frequency ranges correspond to the first-order peaks, while the energy around these local maxima represents the second-order continuum. This is best shown in the individual Doppler spectra plots from the identified events (see Fig. 6, left panels). The deviation of the first-order peak from the Bragg frequency $( \pm 0.701 \mathrm{~Hz})$ is time varying as it depends on surface current speed which is modulated by the prevailing wind and tidal conditions (see Fig. 3). Doppler spectra from events A and B (see Figs. 5 and 6, left panel) are typical examples of highly energetic conditions. They demonstrate the merging of first and second-order parts of the spectrum that makes defining the firstorder peak difficult. 


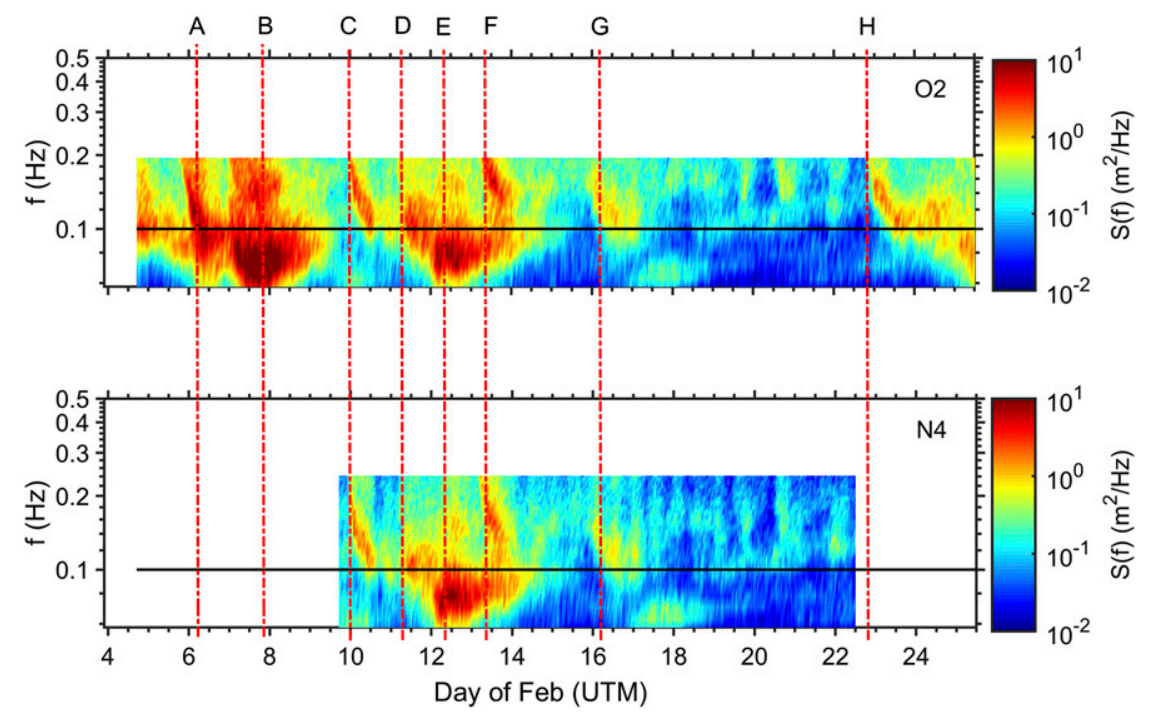

FIG. 4. Time stacks of estimated wave spectra $S(f)$ from sites (top) O2 and (bottom) N4. For instrument locations see Fig. 2. The horizontal black line at $0.1 \mathrm{~Hz}$ denotes the separation of swell and wind wave bands. Vertical dashed lines refer to the time events shown in Fig. 3 (see the text for details).

For each of the Doppler spectra a Gaussian curve was fitted on the Bragg peaks identified using two frequency bins around each peak. The fitted first-order peak was then subtracted from the Doppler spectrum to reduce its potential influence on the second-order sidebands. As in Heron and Heron (1998), the secondorder sidebands surrounding the Bragg peaks were first weighted, using Barrick's (1977b) weighting function; then, they were folded around the Bragg peak frequency and added together for each side separately. Last, they were normalized by the integral of first-order peak energy for each corresponding side according to Eq. (3). The Bragg peak half-width $\Delta f$ in Eq. (3) was determined by the half-width of the Gaussian fit to the Bragg peak. The weighted and normalized second-order spectra from each side were averaged to generate the final $R_{W}(f)$ spectra for sites $\mathrm{O} 2$ and N4. These are shown in Fig. 7 as time stacks, while

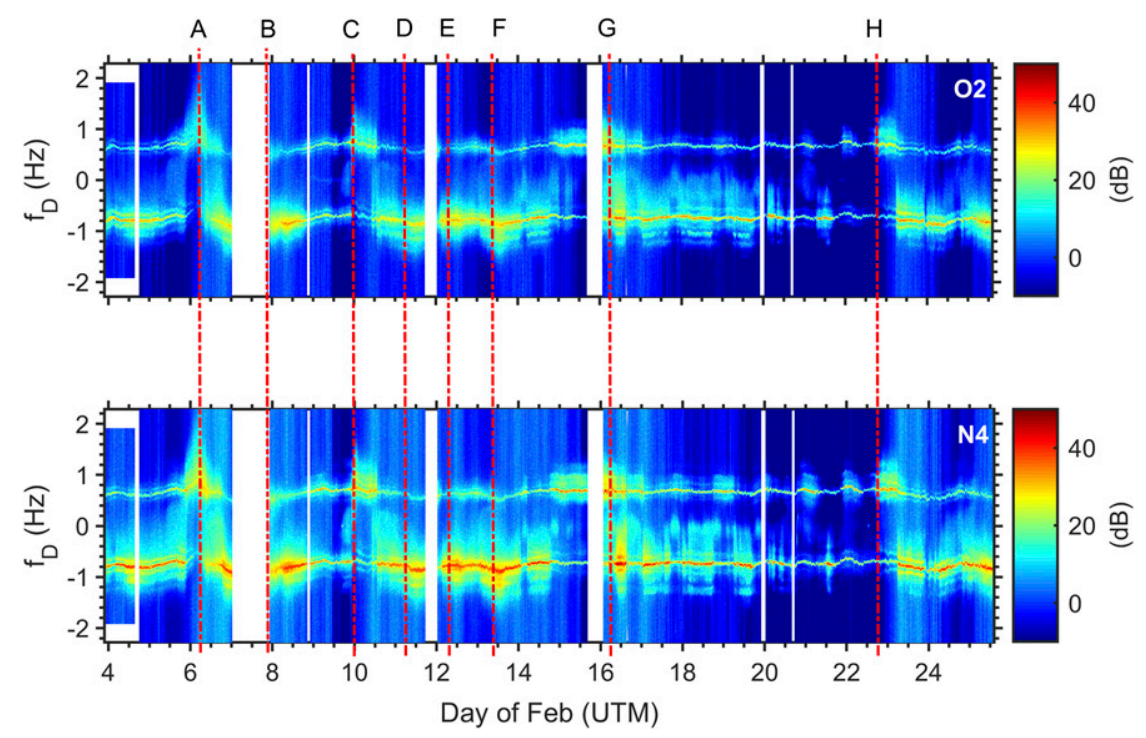

FIG. 5. Time stacks of Doppler backscatter spectra estimated using the 48-MHz VHF radar. Each time stack represents Doppler spectra from the radar beam formed at locations corresponding to the locations of sites (top) O2 and (bottom) N4. Vertical dashed lines refer to the time events shown in Figs. 3 and 4 (see text for details). 

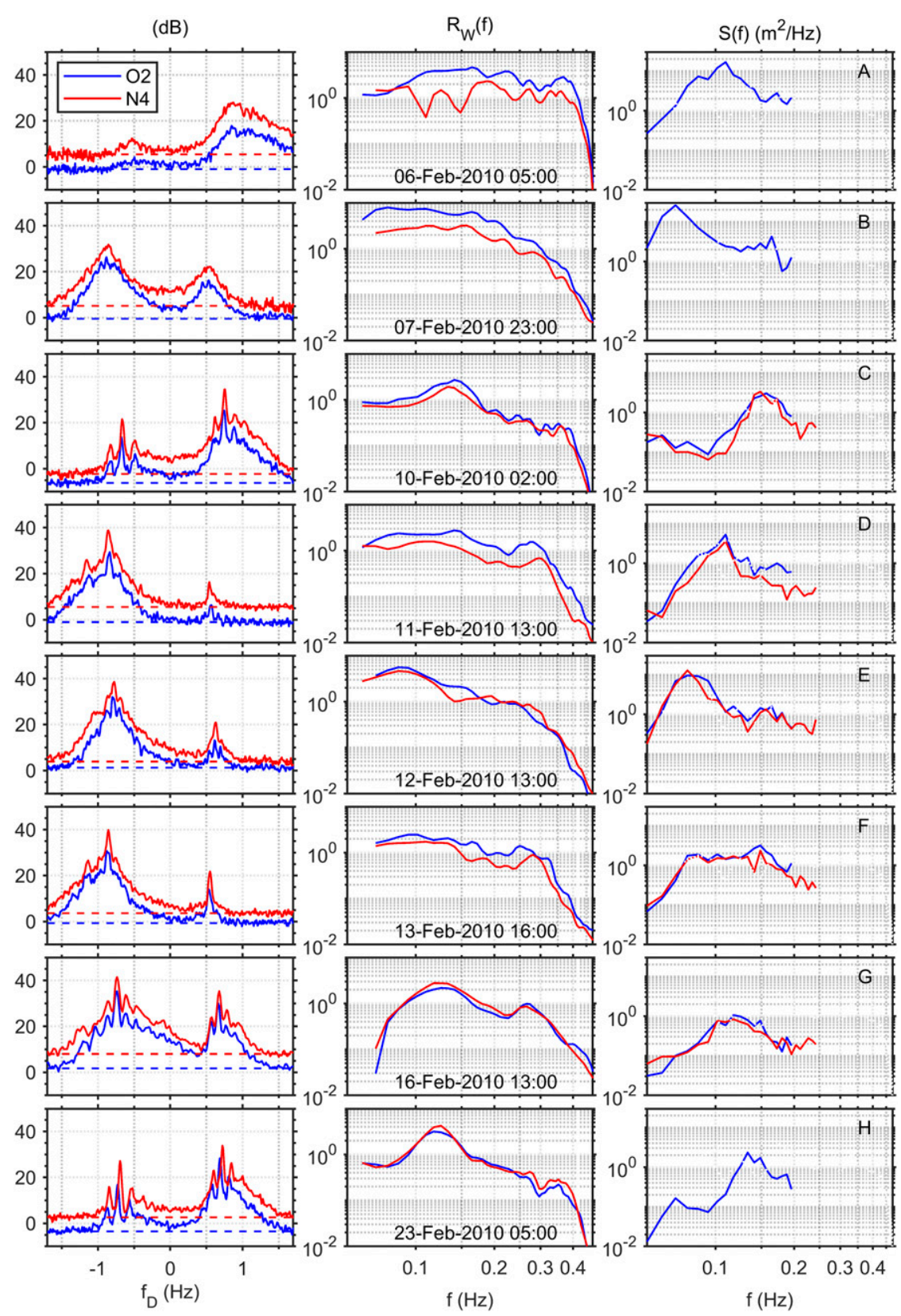

FIG. 6. VHF radar data for events A-H (see Figs. 3-5): (left) individual VHF radar Doppler spectra (the dashed lines denote the noise level for each spectrum), (center) second-order, weighted and normalized spectra $R_{W}(f)$ estimated from the Doppler spectra shown in the left column, and (right) in situ estimates of wave spectra from the acoustic instruments. The blue and red curves correspond to sites $\mathrm{O} 2$ and $\mathrm{N} 4$, respectively.

individual $R_{W}(f)$ for the specific events $\mathrm{A}-\mathrm{H}$ are shown in Fig. 6 (center panels).

\section{d. Wave inversion model calibration}

Prior to estimating the frequency dependent coefficient for wind seas [Eq. (2)] and swell [Eq. (4)], the spectral energy data for each frequency band were quality assured using several criteria. First, an analysis was carried out to ensure that both in situ and radar Doppler spectral estimates were above their corresponding spectral noise floor. For the in situ wave spectra the value of $0.15 \mathrm{~m}^{2} \mathrm{~Hz}^{-1}$ was assumed to be the noise floor, as determined from the spectra. For the selection of the normalized Doppler spectral data 


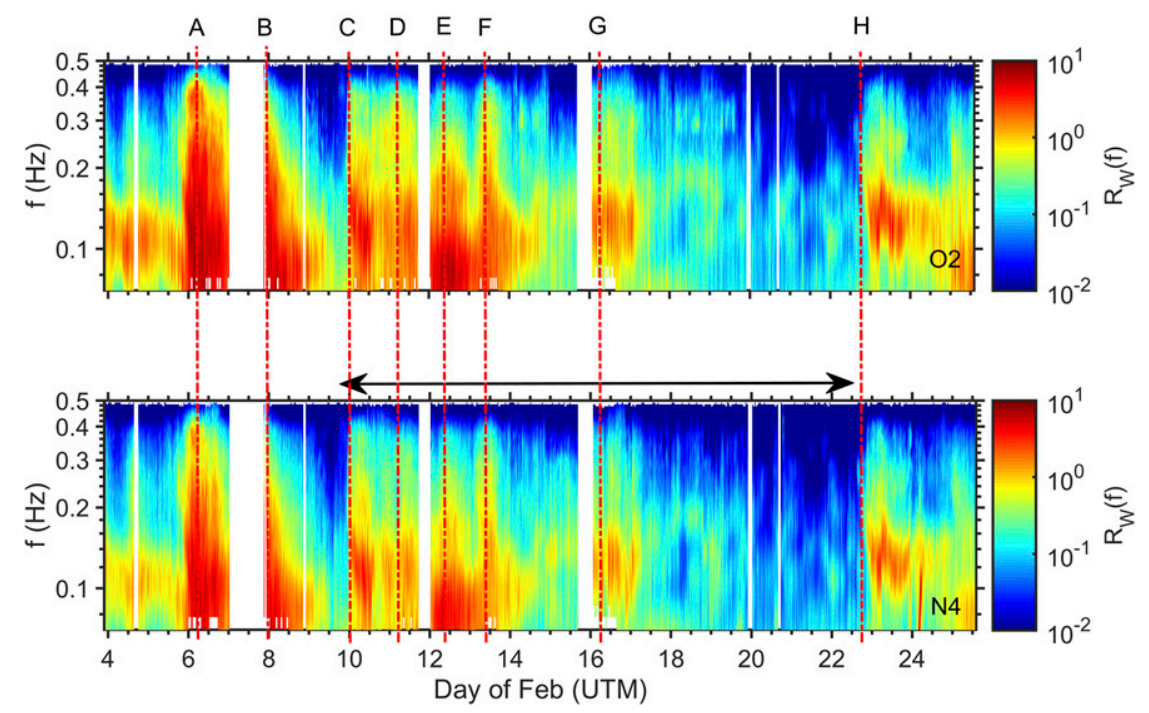

FIG. 7. Time stacks of weighted, normalized second-order radar $\operatorname{spectra} R_{W}(f)$ at sites (top) $\mathrm{O} 2$ and (bottom) N4. The double arrow on the bottom panel defines the period of in situ data availability at site $\mathrm{N} 4$ that was used for calibration.

$\left[R_{W}(f)\right]$, we followed the approach of Wyatt et al. (2005) and Lopez et al. (2016) and only Doppler spectra with energy (SNR) greater than 25 and $10 \mathrm{~dB}$ for the first- and second-order energy peaks, respectively, were selected. The Bragg peak was required to be at least $5 \mathrm{~dB}$ above the second-order sidebands so that it can be clearly identified.

The calibration coefficients corresponding to Eq. (2) estimated using the data that passed these criteria are denoted as $\alpha(f)_{\mathrm{SNR}}$. In addition, a subgroup of the data was created that included only records of wind seas $\left(f_{p}>0.10 \mathrm{~Hz}\right)$, without swell being present. The coefficients derived using these data are denoted as $\alpha(f)_{\mathrm{SNR}}^{+}$.

Because our data are from the nearshore region, we explored the effect that the shallow water depth might have in the calibration by creating three different estimates of $\left.R_{W}(f): 1\right)$ using the deep water weighting function of Barrick (1977b); 2) not applying any weighting at all as in Lopez et al. (2016), and 3) using a shallow water weighting function as suggested in Lipa et al. (2008). The shallow water weighting function was calculated using the forward model of Gill and Walsh (2001). The estimated $R_{W}(f)$ values for each case correspond to discreet ocean wave frequency bands that span the range $0.058-0.500 \mathrm{~Hz}$. These were interpolated to match the frequency bands corresponding to the in situ wave spectra $S_{f}$ estimates, which were limited to 0.19 and $0.25 \mathrm{~Hz}$, for $\mathrm{O} 2$ and $\mathrm{N} 4$, respectively. The corresponding calibration coefficients $\alpha(f)$ were estimated for each $f$, as in Lopez et al. (2016), using a least squares fit between all $S\left(f_{i}\right)$ and the corresponding
$R_{W}\left(f_{i}\right)$ values, from all qualified Doppler spectra and for each frequency band $i$. Although Eq. (2) is to be used for the wind waves only, the fitting was carried out for all frequencies, including swell, as in Lopez et al. (2016), and the results are shown in Fig. 8.

The coefficients estimated using the deep-water weighting function (see Figs. 8a,c) for each site are similar to each other, independent of the data used $\left[\alpha(f)_{\mathrm{SNR}}\right.$ or $\left.\alpha(f)_{\mathrm{SNR}}^{+}\right]$. In the wind wave frequency range $(0.10-0.25 \mathrm{~Hz})$ the coefficients are of similar magnitude across the whole wind wave frequency range, for both cases. However, at lower (swell) frequencies $(<0.10 \mathrm{~Hz}), \alpha(f)_{\mathrm{SNR}}$ values are $3-4$ times the $\alpha(f)_{\text {SNR }}^{+}$ones (see Figs. 8a,c). This discrepancy at the swell band is mainly because the $\mathrm{SNR}^{+}$data do not include conditions with significant swell energy. The correlation coefficient $r$ of $R_{W}(f)$ and $S(f)$ values used to estimate $\alpha(f)_{\mathrm{SNR}}$ range from 0.2 to 0.9 at frequency range $0.058-0.10 \mathrm{~Hz}$ and these values are reduced to $0.4-0.6$ at higher frequencies $(f>0.10 \mathrm{~Hz})$ (see Fig. 8b). These correlations are similar to those reported by Lopez et al. (2016). Relative to $\alpha(f)_{\mathrm{SNR}}$, the correlations for $\alpha(f)_{\mathrm{SNR}}^{+}$exhibited greater variability $(0.2-0.8)$ and overall lower values for frequencies $<0.1 \mathrm{~Hz}$ (swell band), and somewhat more consistent values $(0.4-0.6)$ for frequencies $>0.1 \mathrm{~Hz}$.

The $\alpha(f)_{\text {SNR }}^{+}$vales determined without applying the weighting function for $R_{W}$ are shown in Fig. 8e. The values shown are smaller by a factor of 2.7 than those estimated using the deep-water weighting function and exhibit an identical distribution over the frequency range. This is mainly because the weighting 

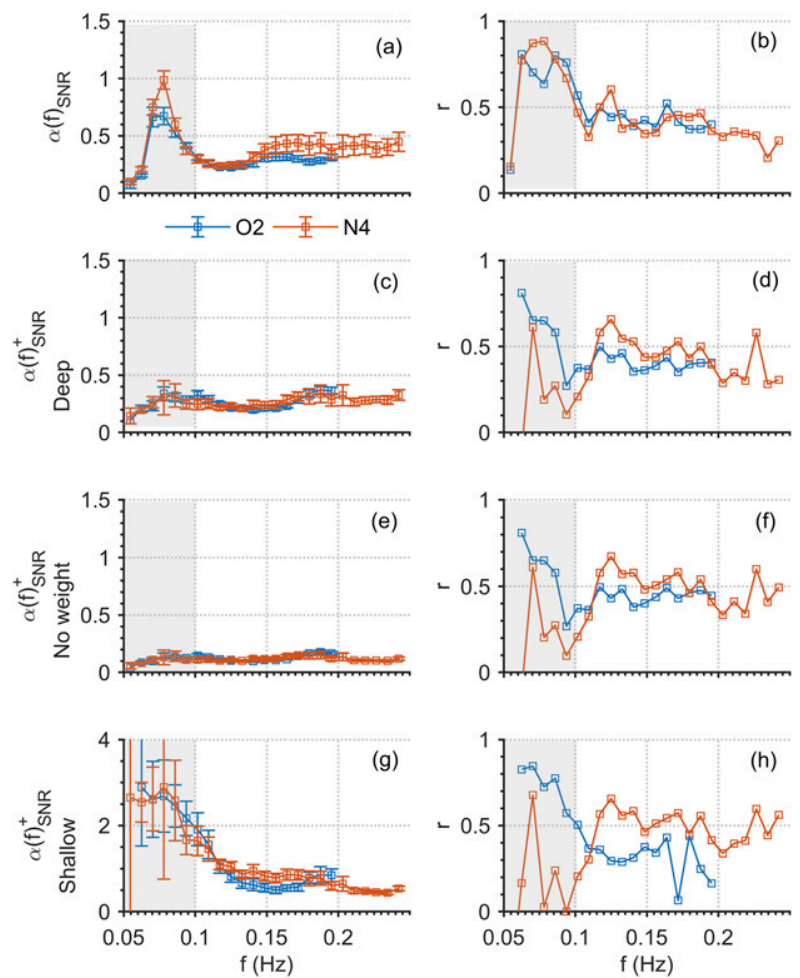

FIG. 8. Estimates of frequency-dependent empirical calibration coefficients [Eq. (2)] using Doppler spectra that satisfied the (a) SNR and (c),(e),(g) SNR + criteria (see text for details) at all sites. The $\alpha_{\mathrm{SNR}}^{+}$values were determined from normalized secondorder spectra weighted using a deep-water weighting function [(c)], with no weighting applied [(e)], and weighted using a shallow water weighting function $[(\mathrm{g})]$. (b),(d),(f),(h) The corresponding linear correlation coefficients. The shaded area in the diagrams delineates the swell frequency range.

function for our radar frequency is almost flat over the wave frequency range used in this study (for more details see section 5a). Use of the shallow water weighting function (Fig. $8 \mathrm{~g}$ ) makes the regression coefficients more frequency dependent with their values increasing toward lower wave frequencies. This also introduces a variability between sites that is due to the different water depths.

For the swell wave module, the spreading parameter $\sigma$ [see Eq. (5)] was estimated by fitting a Gaussian curve to the swell peaks found in the in situ wave spectra. Histograms of the distribution of the estimated $\sigma$ values, for each site, are shown in Figs. 9a and 9b. A skewed distribution is revealed, with 0.010 and $0.009 \mathrm{~Hz}^{2}$ being the peak values for sites $\mathrm{O} 2$ and $\mathrm{N} 4$, and their mean value $\left(\sigma=0.0095 \mathrm{~Hz}^{2}\right)$ was used. The swell calibration coefficient $\alpha_{s}$ was estimated using a least squares regression fit to Eq. (4); values of $0.05 \pm$ 0.013 and $0.07 \pm 0.009$ were derived for $\mathrm{O} 2$ and $\mathrm{N} 4$, respectively (see Figs. 9c,d).
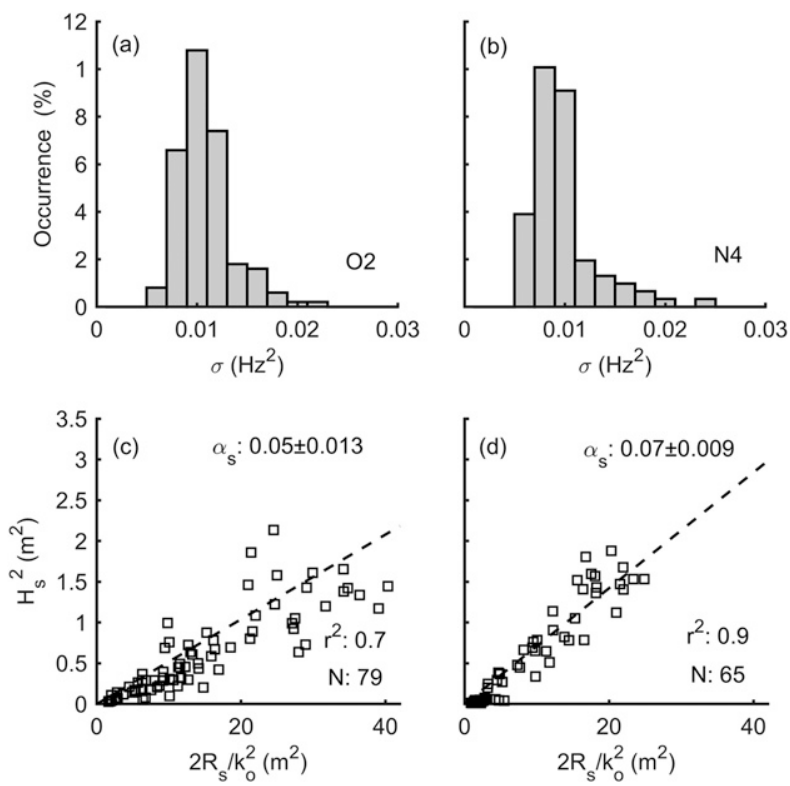

FIG. 9. (a),(b) Histograms showing the distribution of the spreading coefficient $\sigma$ for swell, estimated from the in situ wave spectra, and (c),(d) plots of regression analysis used to estimate the calibration coefficient $\alpha_{s}$ in the swell module for sites (left) $\mathrm{O} 2$ and (right) N4.

\section{e. Application of the wave inversion model}

\section{1) CALibration Sites: O2 AND N4}

In this section, the coefficients estimated during calibration (see section above) using the deep-water weighting function are used to invert the radar-derived Doppler spectra from sites $\mathrm{O} 2$ and N4 into surface wave spectra.

Prior to the inversion, the ratio of swell over wind wave energy in the normalized second-order Doppler spectrum, defined as

$$
L=\frac{\sum_{i} R_{W}\left(f_{i}<f_{c}\right)}{\sum_{i} R_{W}\left(f_{i} \geq f_{c}\right)},
$$

is used to identify Doppler spectra with significant energy in the swell band. If $L>1$, the swell module [Eq. (5)] is used to estimate the wave energy at frequencies $f<f_{c}$ using the site-specific $\alpha_{s}$ value ( 0.05 and 0.07 for $\mathrm{O} 2$ and $\mathrm{N} 4$, respectively). The wind wave spectrum [Eq. (2)] is calculated for $f \geq f_{c}$, if $L>1$, and for all frequencies (including swell) if $L \leq 1$. Because of the relatively small variability of $\alpha(f)_{\text {SNR }}^{+}$, using the deep water weighting function along the wind wave frequency range (see Fig. 8c), and the similarity of the frequencyaveraged values between sites $(0.26 \pm 0.01$ and $0.25 \pm$ 0.02 for $\mathrm{O} 2$ and $\mathrm{N} 4$, respectively), the frequency- and 

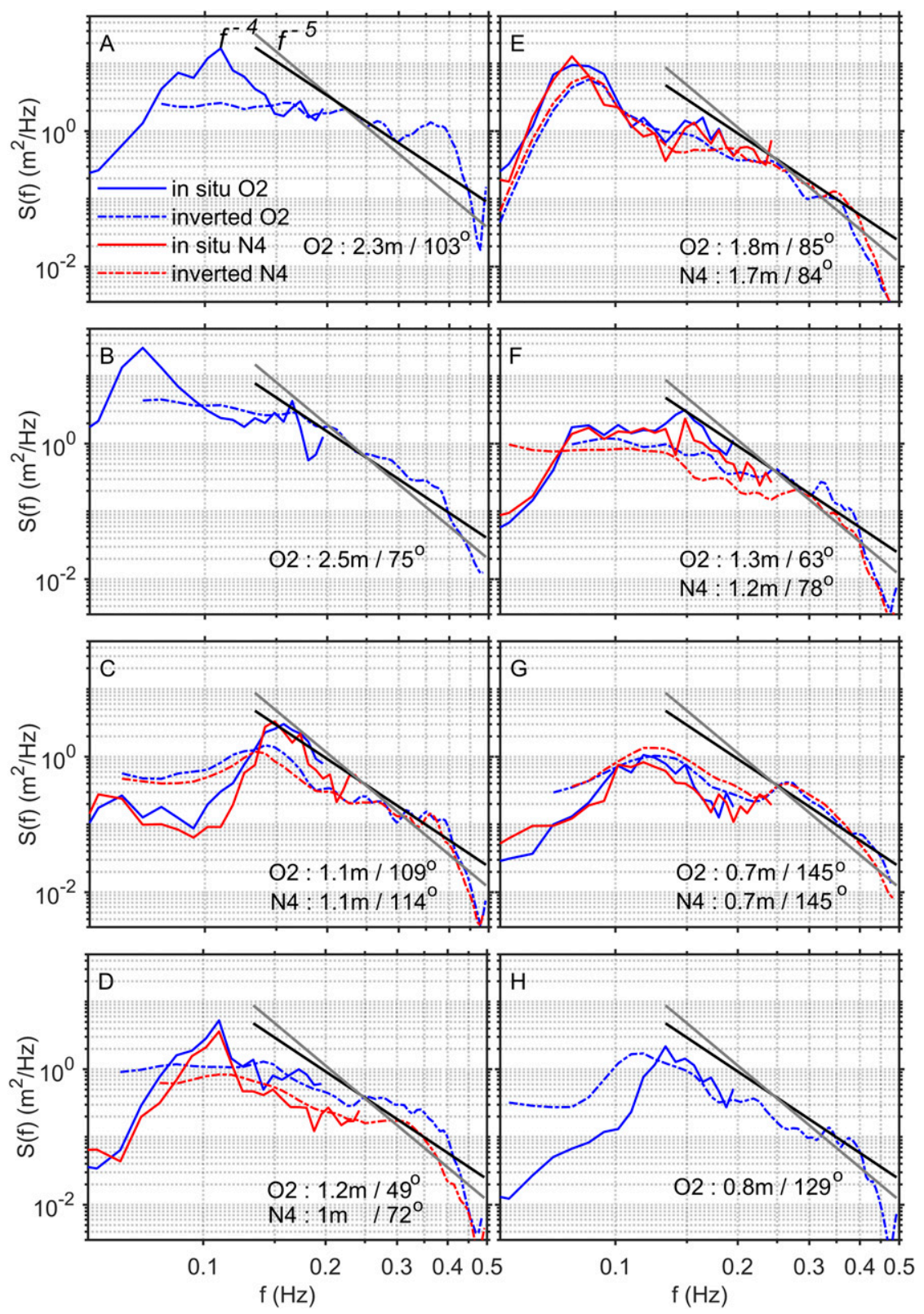

FIG. 10. Examples of in situ (solid curves) and inverted (dashed curves) wave spectra for events A-H (see Figs. 3 and 4) and for sites O2 (blue) and N4 (red). The $f^{-4}$ and $f^{-5}$ asymptotes are shown as black and gray lines, respectively. The corresponding in situ wave height/mean wave direction are shown in each panel.

site-averaged value of 0.255 is used. The inversion is carried out to frequencies up to $0.5 \mathrm{~Hz}$ which is higher than the maximum frequency of the energy spectra estimated using the acoustic instruments $(0.19$ and $0.25 \mathrm{~Hz}$, for $\mathrm{O} 2$ and $\mathrm{N} 4$, respectively); the inverted wave spectra corresponding to the individual events $\mathrm{A}-\mathrm{H}$ are shown in Fig. 10. Note that the same analysis for the wind waves was carried out using the nonweighted normalized spectra, and the results were almost identical and are not shown in here. Similar results (not shown here) were obtained using the shallow water weighting function; however, this required the use of coefficients that are different for each frequency but also vary between sites.

Events A and B (in situ RMS wave heights of 2.3 and $2.5 \mathrm{~m}$, respectively) are examples of spectra with Bragg peaks that are less than $5 \mathrm{~dB}$ above the second-order sidebands. Although these spectra are within Barrick's (1977a,b) wave height limits $\left(0.42<H_{\text {rms }}<2.82 \mathrm{~m}\right.$, for a 48-MHz system), they do not meet the signal quality criteria. They are shown in here as a demonstration of the 

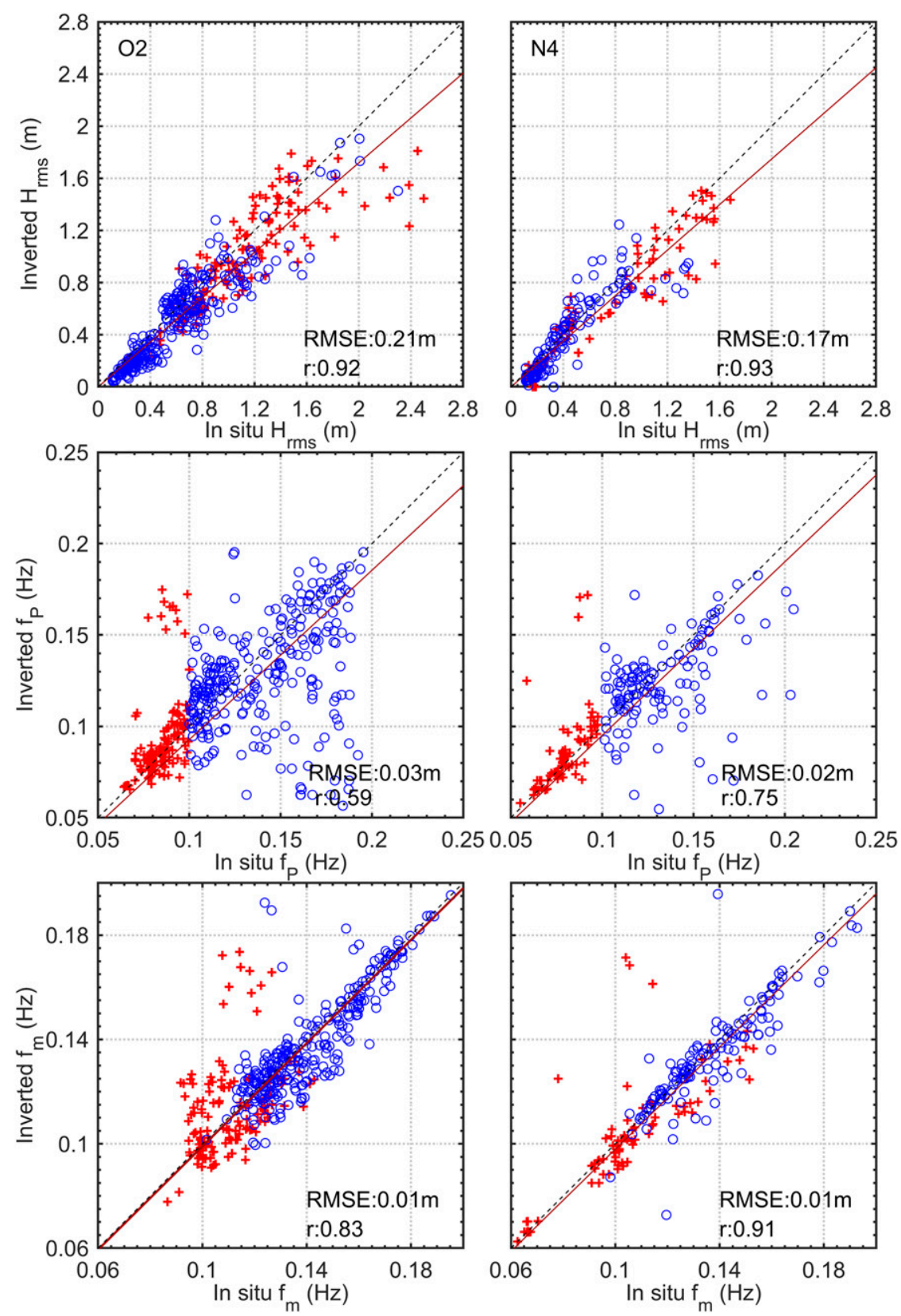

FIG. 11. Comparison of wave bulk parameters $\left[H_{\mathrm{rms}}\right.$, peak $\left(f_{P}\right)$ and mean $\left(f_{m}\right)$ wave frequency] for sites (left) O2 and (right) N4. The 1:1 line (dashed) and the best regression line (red) are also shown. Red plus signs and blue open circles denote conditions that are dominated by swell and wind waves, respectively.

effectiveness of this criterion to identify Doppler spectra not suitable for wave inversion. The wave inversion fails to identify the peak of the wave spectrum and the in situ wind sea spectra match the inverted one only at high frequencies. During event $\mathrm{E}$, although the total wave height is $1.75 \mathrm{~m}$, the partitioned wind wave height is $1 \mathrm{~m}$ and the spectrum is reconstructed accurately. Similar agreements between the inverted and in situ spectra can be seen in events $\mathrm{C}$ and $\mathrm{D}$ which are characterized by wind sea spectra only (no swell) but with a smaller wave height $(1 \mathrm{~m})$. For the remaining events $(\mathrm{F}, \mathrm{G}$, and $\mathrm{H})$, the reconstructed spectra bear a resemblance to the ones estimated from the in situ data (see the corresponding panels in Fig. 10).

In Fig. 11 bulk wave parameter estimates (i.e., RMS wave height, mean, and peak wave frequency) 
TABLE 3. RMS error, linear correlation coefficient, and regression slope derived from the comparison of wave bulk parameters for total and partitioned RMS wave height estimates from the inverted and in situ spectra for all sites. Note: sites O2 and N4 were used for the calibration of the model.

\begin{tabular}{|c|c|c|c|c|c|c|c|c|c|c|}
\hline & \multirow[b]{2}{*}{$N$} & \multicolumn{3}{|c|}{$H_{\text {rms }}($ total $)$} & \multicolumn{3}{|c|}{$H_{\mathrm{rms}}($ swell $)$} & \multicolumn{3}{|c|}{$H_{\mathrm{rms}}$ (wind waves) } \\
\hline & & Error $(\mathrm{m})$ & $r$ & Slope & Error $(\mathrm{m})$ & $r$ & Slope & Error $(\mathrm{m})$ & $R$ & Slope \\
\hline $\mathrm{O} 2$ & 413 & 0.21 & 0.92 & 0.86 & 0.23 & 0.83 & 0.78 & 0.17 & 0.89 & 0.89 \\
\hline N1 & 407 & 0.16 & 0.92 & 0.91 & 0.18 & 0.82 & 0.86 & 0.13 & 0.90 & 0.91 \\
\hline N2 & 306 & 0.19 & 0.94 & 0.80 & 0.22 & 0.88 & 0.72 & 0.13 & 0.89 & 0.84 \\
\hline N3 & 450 & 0.20 & 0.93 & 0.79 & 0.16 & 0.89 & 0.80 & 0.17 & 0.90 & 0.75 \\
\hline N4 & 214 & 0.17 & 0.93 & 0.89 & 0.15 & 0.91 & 0.89 & 0.14 & 0.90 & 0.86 \\
\hline N5 & 334 & 0.17 & 0.92 & 0.94 & 0.21 & 0.79 & 0.85 & 0.14 & 0.92 & 0.95 \\
\hline N6 & 627 & 0.25 & 0.86 & 1.04 & 0.23 & 0.73 & 0.87 & 0.21 & 0.85 & 1.09 \\
\hline
\end{tabular}

from the inverted wave spectra are compared with estimates from the in situ spectra. Wave height RMS errors are 0.21 and $0.17 \mathrm{~m}$ for sites $\mathrm{O} 2$ and $\mathrm{N} 4$, respectively. The linear correlation coefficients are high ( 0.92 and 0.93 , respectively) while the linear regression slope is 0.86 and 0.89 , respectively (see Table 3). Note that the in situ wave spectra are also estimates and do not constitute absolute measurements of the true sea state; as such the error estimates presented above represent an assessment of the agreement between the two methods. However, independent evaluation of ADCPs for wave measurements with wave buoys (e.g., Work 2008) have revealed RMSEs of $0.08 \mathrm{~m}, 2.6 \mathrm{~s}$, and $0.7 \mathrm{~s}$ for wave height, peak, and mean wave period, respectively, and $11^{\circ}$ for mean wave direction. These values provide a basis for the evaluation of the agreement found between the wave parameter estimates from the inversion method and in situ instrumentation.

\section{2) VERIFICATION SITES}

The inversion method is verified using Doppler spectra from sites $\mathrm{N} 1, \mathrm{~N} 2, \mathrm{~N} 3, \mathrm{~N} 5$, and N6, that were not used in the calibration process, utilizing the coefficients derived from sites $\mathrm{O} 2$ and N4. For the wind wave module, the frequency and site averaged value for $\alpha(f)_{\mathrm{SNR}}^{+}$, as estimated using the deepwater weighting function, is used $(=0.255)$, and for the swell module the mean of the corresponding values for the two calibration sites $(=0.06)$ is adopted. For brevity, only the results for sites N1 and N5 are presented in detail (see Fig. 12). The results of the statistical analysis for all sites are listed in Tables 3 and 4. As shown earlier, the Bragg peaks at events $A$ and $\mathrm{B}$ are poorly defined, as they are less than $5 \mathrm{~dB}$ above the second-order sidebands (Fig. 6). The peak of the wave spectrum is significantly underestimated in $\mathrm{A}$ and entirely missed in $\mathrm{B}$, but the inverted spectra (see Fig. 12) agree relatively well with the in situ ones at higher (wind wave) frequencies. Agreement in the wind wave band is found also for event $\mathrm{C}$, although in this case the inverted spectrum contains more energy in the swell band than what is present in situ; at the same time the inverted spectra underestimate the peak wave energy. Events $\mathrm{E}$ and $\mathrm{F}$ show the best agreement between inverted and in situ data with event $\mathrm{E}$ being the best overall, even though the total wave height is $1.5 \mathrm{~m}$, higher than those for other events (C, D, F, G, and H). For event $\mathrm{D}$, there is good agreement between the two spectra for site N1, but for site N5 the inverted spectrum overestimates the energy present in higher frequencies.

The inverted and in situ estimated bulk wave parameters (RMS wave height, mean, and peak wave frequency) are compared in Fig. 13 while the corresponding RMS errors and correlation coefficients of both total and partitioned wave heights and mean and peak periods are listed in Tables 3 and 4. Overall, they are of similar value as those estimated for the sites used in the calibration but the wave height errors are higher for swell than that for wind waves. The latter errors are smaller than the ones for the total wave height. Data from periods of common data availability are used to estimate the wave height differences (in terms of RMS error) between stations for both the in situ and the inverted wave height estimates (see Table 5). The spatial differences between in situ wave heights range from $0.03 \mathrm{~m}$ (sites $\mathrm{N} 6-\mathrm{N} 2$ ) to $0.19 \mathrm{~m}$ ( sites $\mathrm{N} 2-\mathrm{O} 2$ ). The corresponding differences between inverted values range from $0.1 \mathrm{~m}$ (sites $\mathrm{N} 4-\mathrm{N} 3$ ) to $0.39 \mathrm{~m}$ ( sites N6 - N3). Overall differences of in situ measurements between different sites are slightly greater $(25 \%-30 \%)$ when using the inverted wave heights. The exception is station N6 where the inverted heights from this site show a much higher error when compared with those from the other sites.

\section{f. Directional characteristics}

The ambiguity in the wind and wave direction results (due to the use of a single station) was resolved 

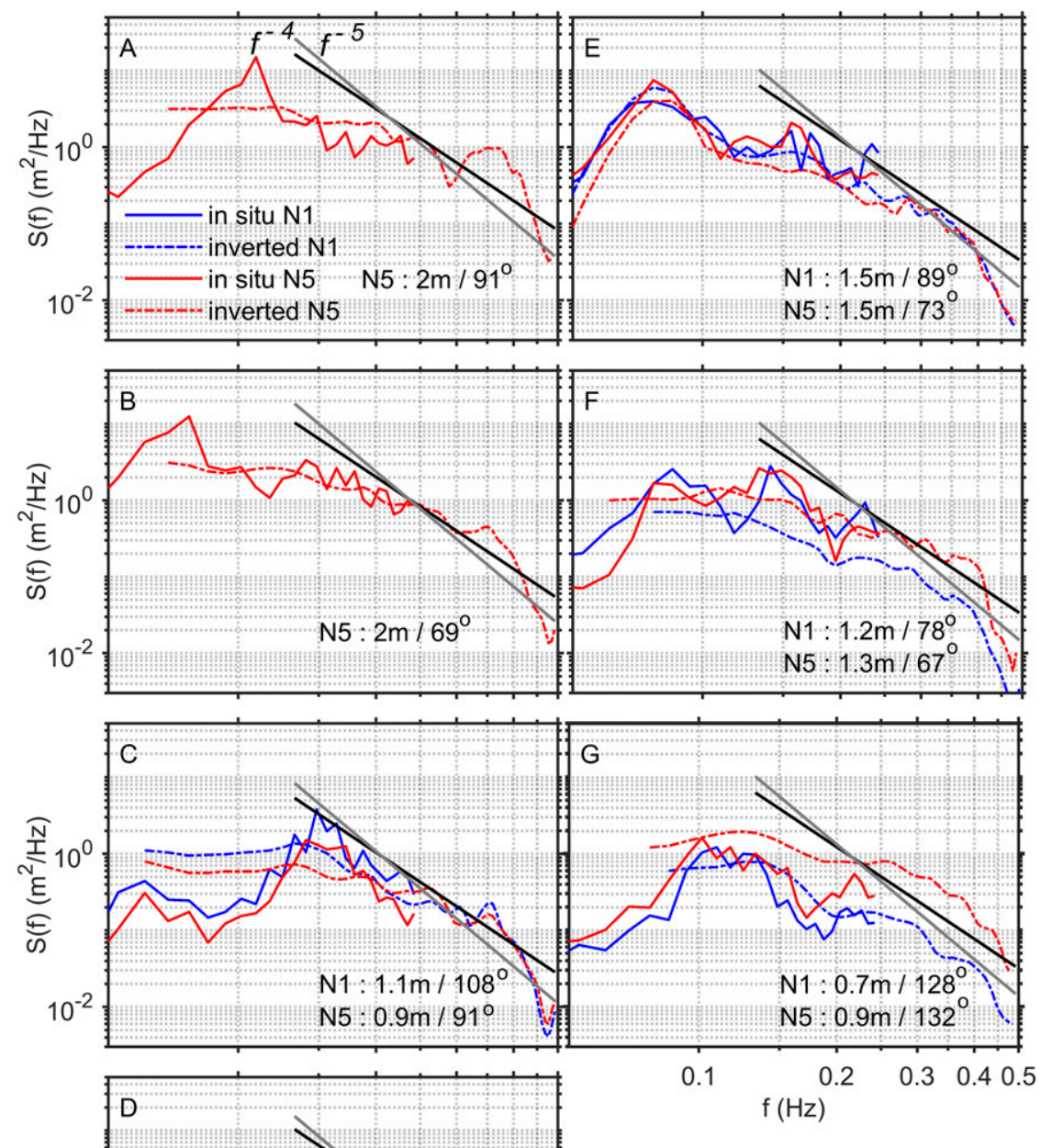

FIG. 12. Examples of inverted (dashed curves) and in situ (solid curves) wave spectra for events A-G (see Figs. 3 and 4) and for sites N1 (blue) and N5 (red). The $f^{-4}$ and $f^{-5}$ asymptotes are shown as black and gray lines, respectively. The corresponding in situ wave height/mean wave direction are shown in each panel.

using the in situ wind and wave measurements from the NOAA buoy and the in situ sites, respectively. Although this is not possible when no in situ data are available, we use this approach to evaluate the accuracy of a single VHF radar system in obtaining these angles. A complex correlation analysis (see Kundu 1976) was carried out to examine the agreement between the in situ and inverted directional estimates. Prior to analysis the directional data were converted into vectors with magnitude equal to the wave height and direction the corresponding wave (or wind) direction. This allows the suppression of erroneous errors in direction occurring during periods of low wave energy.
A comparison of the wind direction results derived from the first-order peaks, from all sites, against the wind direction observations from the offshore NOAA buoy 41025 is shown in Fig. 14 (left panels). The wind direction estimates are in general agreement with the measurements despite the fact that winds offshore might not be identical to those in the nearshore (e.g., Wu et al. 2017). The complex correlation coefficients were found to vary between 0.68 and 0.75 with their corresponding angle varying from $9^{\circ}$ to $16^{\circ}$ (see Table 6).

In a similar manner, the wave direction for each frequency component (up to $0.5 \mathrm{~Hz}$ ) for events $\mathrm{A}-\mathrm{H}$ are estimated using Eq. (9) and are shown in Fig. 15. 
TABLE 4. As in Table 3, but for mean and peak frequency and mean and peak wave period.

\begin{tabular}{|c|c|c|c|c|c|c|c|c|c|c|c|c|c|}
\hline & \multirow[b]{2}{*}{$N$} & \multicolumn{3}{|c|}{ Peak frequency $\left(f_{P}\right)$} & \multicolumn{3}{|c|}{ Mean frequency $\left(f_{m}\right)$} & \multicolumn{3}{|c|}{ Peak period $\left(T_{P}\right)$} & \multicolumn{3}{|c|}{ Mean period $\left(T_{m}\right)$} \\
\hline & & Error $(\mathrm{Hz})$ & $r$ & Slope & Error $(\mathrm{Hz})$ & $r$ & Slope & Error (s) & $r$ & Slope & Error (s) & $r$ & Slope \\
\hline $\mathrm{O} 2$ & 413 & 0.03 & 0.60 & 0.93 & 0.01 & 0.80 & 0.90 & 1.93 & 0.68 & 0.90 & 0.84 & 0.80 & 0.99 \\
\hline N1 & 407 & 0.02 & 0.69 & 0.95 & 0.01 & 0.90 & 0.98 & 1.63 & 0.71 & 0.90 & 0.82 & 0.94 & 1.02 \\
\hline $\mathrm{N} 2$ & 306 & 0.02 & 0.76 & 0.97 & 0.01 & 0.90 & 1.01 & 1.68 & 0.79 & 1.01 & 0.81 & 0.95 & 0.99 \\
\hline N3 & 450 & 0.02 & 0.77 & 0.97 & 0.01 & 0.90 & 0.98 & 1.38 & 0.84 & 0.99 & 0.79 & 0.95 & 1.02 \\
\hline N4 & 214 & 0.02 & 0.75 & 0.95 & 0.01 & 0.90 & 0.98 & 1.61 & 0.76 & 0.99 & 0.82 & 0.94 & 1.01 \\
\hline N5 & 334 & 0.03 & 0.58 & 0.94 & 0.01 & 0.80 & 1.01 & 2.03 & 0.64 & 1.02 & 0.79 & 0.83 & 0.99 \\
\hline N6 & 627 & 0.03 & 0.51 & 0.94 & 0.01 & 0.80 & 1.02 & 2.16 & 0.51 & 0.99 & 0.81 & 0.90 & 0.98 \\
\hline
\end{tabular}

Overall, the in situ and radar-derived wave directions for both calibration (O2 and $\mathrm{N} 4)$ and verification (N1 and N5) locations show good agreement. The corresponding estimates for mean and peak wave directions are compared against the in situ estimates in Fig. 14 (panels in middle and left column, for mean and peak energy wave direction, respectively) while the results of the complex correlation analysis for all sites available are listed in Table 6. For mean wave direction, the magnitude of the complex correlation coefficients ranges from 0.65 to 0.80 while their angles range from $-33^{\circ}$ to $9^{\circ}$. The smallest and larger magnitude of the correlation correspond to sites $\mathrm{O} 2$ and N4, respectively. The comparison of peak wave direction shows lower magnitude in complex correlation ranges $0.48-0.70$ with angle in correlations from $-34^{\circ}$ to $10^{\circ}$.

\section{Discussion}

\section{a. The wave inversion model}

The calibration of the hybrid empirical wave inversion model presented in section 2 produced calibration coefficients that were very similar between the two calibration sites (O2 and $\mathrm{N} 4)$, despite their difference in range (3.3 and $2.0 \mathrm{~km}$. respectively) and beam angle (22.3 ${ }^{\circ}$ and $38.2^{\circ}$, respectively). This was particular the case for the wind wave module $(f>0.10 \mathrm{~Hz})$ when we excluded spectra with significant energy in the swell band (see Fig. 8c). These findings were similar to those obtained with or without (not shown here) applying the deep-water weighting function. Also, our coefficients show little variability with frequency which contrasts the findings of Lopez et al. (2016), who noted a greater variability of the coefficients with frequency even within the wind frequency range. In their case, as in Gurgel et al. (2006), the second-order spectra were not weighted using Barrick's weighting function, prior to normalization by the integral of the first order $\left(\sigma_{1}\right)$.

Despite the satisfactory performance of the inversion method when not weighting the second-order spectrum, application of the weighting function allows compensation for the second harmonic and corner reflector peaks $\left(2^{1 / 2} f_{B}\right.$ and $2^{3 / 4} f_{B}$, respectively) which can be found only in the outer Doppler sidebands, as shown in Fig. 16. This asymmetry cannot be captured by the calibration coefficients alone as these are applied on the two-side averaged normalized second-order Doppler spectrum. This is demonstrated in Fig. 17, where a few examples of normalized secondorder spectra are shown with and without applying the weighting function. The harmonic peaks at $2^{1 / 2} f_{B}$ are clearly visible in the wave spectra with no weighting; these peaks are suppressed when weighting is applied. Wave spectra from the offshore buoy, located some $29 \mathrm{~km}$ offshore, do not show any wave energy being present in these frequencies confirming that these peaks are harmonics. Our in situ data do not extend to those frequencies, so these effects do not affect the inversion method. Lopez et al. (2016) reported that the harmonics and corner reflection peaks might be influencing the accuracy of their inversion and this was used to explain some of the discrepancies they encountered. Failing to apply the weighting function to suppress these peaks may result in minima in the calibrations coefficients, as Lopez noted occurred in their calibration at $2^{1 / 2} f_{B}$. Note that these peaks correspond to different ocean wave frequencies depending on the radar frequency (see Fig. 17). Furthermore, application of the weighting function may be used to eliminate the dependency of the calibration factor to HF radar operational frequency and wind wave frequency; this has the implication that potentially a single, empirical coefficient may be applicable to all radar and wind wave frequencies, something that we are currently investigating.

The use of Barrick's (1977b) deep-water weighting function in our calibration lead to deriving a coefficient value which is consistent with those from other theoretical studies for deep water conditions. Although the shallow waters of our experimental site suggest that a shallow water coupling coefficient should be used, 

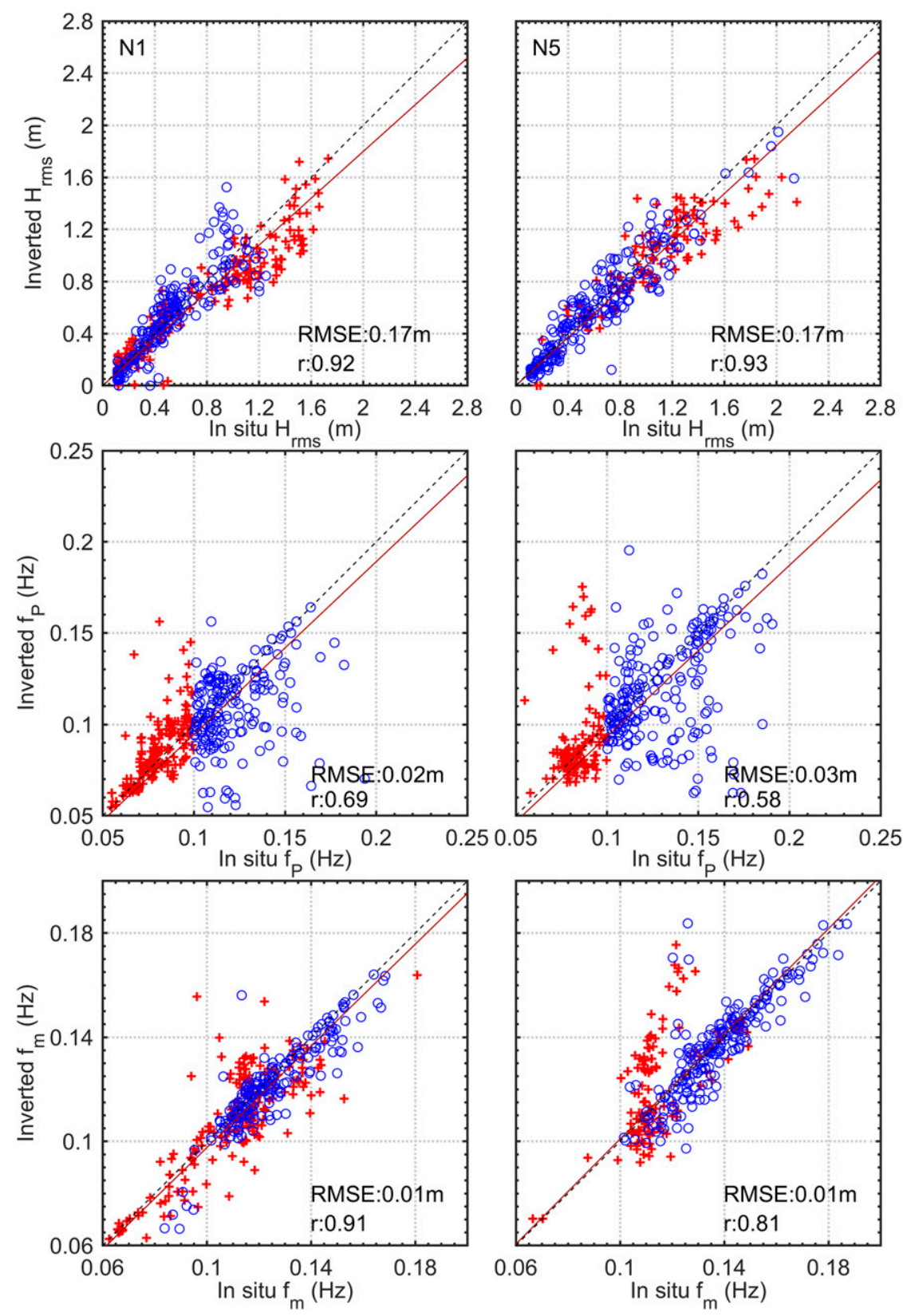

FIG. 13. As in Fig. 11, but for sites (left) N1 and (right) N5.

its use in here did not produce any improvements in the inversion. Its effect was to modify the values of the calibration coefficient making it as frequency dependent parameter (see Fig. 8g). Furthermore, a close examination of the VHF-derived Doppler spectra from three stations, corresponding to three different water depths (see Fig. 18), does not reveal any significant shallow water effects on the evolution of the Doppler spectra, as no frequency shift of the swell peaks due to depth variation between sites is observed. This is in agreement with Lipa et al. (2008) who noted that shallow water effects are more relevant to lower frequency HF radars, at extremely shallow waters. However, in most cases lower frequency $\mathrm{HF}$ radars operate at coarser range resolutions and as such rarely produce data in the inner shelf region, except in very gently sloped continental shelves.

As we showed earlier (see Figs. 8c,e) the calibration coefficients estimated with and without using the weighting function do not vary significantly, except for a scaling factor of $\sim 2.7$. This is because for our operating frequency $(48 \mathrm{MHz})$, the harmonic and corner reflection peaks appear at ocean wave frequencies 0.29 
TABLE 5. RMS errors ( $\mathrm{m}$; bottom left) and linear correlation coefficient estimates (top right) between sites, for both in situ and HF radar inverted estimates. Values shown were obtained using data $(N=155)$ when all sites were operational. The values shown in each table cell are listed as in situ/inverted values.

\begin{tabular}{|c|c|c|c|c|c|c|c|c|c|}
\hline & $\mathrm{O} 2$ & N1 & $\mathrm{N} 2$ & N3 & N4 & N5 & N6 & $\mathrm{HF}$ & \\
\hline & 1 & $0.97 / 0.89$ & $0.97 / 0.9$ & $0.97 / 0.9$ & $0.97 / 0.91$ & $0.96 / 0.87$ & $0.95 / 0.78$ & 0.92 & $\mathrm{O} 2$ \\
\hline & & 1 & $0.98 / 0.84$ & $0.98 / 0.9$ & $0.98 / 0.92$ & $0.96 / 0.8$ & 0.970 .71 & 0.87 & N1 \\
\hline $\mathrm{O} 2$ & 1 & & 1 & $0.99 / 0.92$ & $0.99 / 0.88$ & $0.95 / 0.84$ & $0.96 / 0.74$ & 09 & $\mathrm{~N} 2$ \\
\hline N1 & $0.17 / 0.16$ & 1 & & 1 & $0.99 / 0.96$ & $0.96 / 0.85$ & $0.97 / 0.75$ & 0.9 & N3 \\
\hline N2 & $0.19 / 0.16$ & $0.09 / 0.17$ & 1 & & 1 & $0.97 / 0.83$ & $0.98 / 0.74$ & 0.9 & N4 \\
\hline N3 & $0.15 / 0.17$ & $0.09 / 0.14$ & $0.09 / 0.11$ & 1 & & 1 & $0.96 / 0.86$ & 0.99 & N5 \\
\hline N4 & $0.15 / 0.15$ & $0.09 / 0.13$ & $0.08 / 0.15$ & $0.08 / 0.1$ & 1 & & 1 & 0.76 & N6 \\
\hline N5 & $0.12 / 0.22$ & $0.14 / 0.23$ & $0.17 / 0.25$ & $0.13 / 0.26$ & $0.13 / 0.25$ & 1 & & 1 & $\mathrm{HF}$ \\
\hline N6 & $0.17 / 0.35$ & $0.11 / 0.35$ & $0.03 / 0.38$ & $0.11 / 0.39$ & $0.1 / 0.38$ & $0.12 / 0.22$ & 1 & & \\
\hline $\mathrm{HF}$ & 0.17 & 0.19 & 0.18 & 0.21 & 0.17 & 0.19 & 0.34 & 1 & \\
\hline
\end{tabular}

and $0.48 \mathrm{~Hz}$, respectively (see Fig. 16), which are beyond the frequency range of our calibration $(0-0.25 \mathrm{~Hz})$. For lower radar frequencies, the peaks appear within the wave frequencies of interest (see Fig. 16) making the use of the weighting function a necessity. This argument is also supported by the disagreement between the Lopez et al. (2016) calibration coefficients with those suggested by Gurgel et al. (2006) even after applying the suggested scaling for radar frequency. It is notable that our frequency averaged calibration coefficient values are very similar to those reported by other studies that used different radar frequencies but implemented the weighting function. Heron and Heron (1998) and Ramos et al. (2009) using Eq. (1) found calibration constant $\zeta=0.55$ and 0.58 , respectively. Since $\alpha=\zeta^{2}$ [see Eq. (1) and Eq. (2)] our wind sea calibration constant $(\alpha=0.255)$ is equivalent to $\zeta=0.504$, which closely agrees with these previous studies, suggesting a constant value across different HF radar systems and frequencies.

When swells are present, the calibration coefficients (Fig. 8a) of the wind module in the lower-frequency bands $(f<0.10 \mathrm{~Hz})$ resemble those of Gurgel et al. (2006) and Lopez et al. (2016). At these frequencies the variability does not depend on the use of the weighting function as it is almost flat over this frequency range (see Fig. 16) for both sides around the Bragg peak. In Lopez et al. (2016), calibrations against different sites revealed a tendency for larger values when swell crosses the radar beam at angles close to perpendicular and smaller values when swell is aligned with the radar beam direction. Because of swell's singular directional characteristics, the wind wave model underestimates the swell spectral energy when swell crosses the radar beam perpendicularly and overestimates it when swell propagates parallel to the radar beam. In the conditions encountered in this study, swell always propagated close to perpendicular to the radar beam, resulting in the larger calibration coefficient values as shown in Fig. 8a when swell was included in the calibration. This justifies the use of a hybrid model, like the one presented in this study, that treats swell and wind waves differently.

Previous swell models (Lipa and Barrick 1980; Bathgate et al. 2006) define $R_{s}$ as being proportional to $H_{s}^{2} \cos ^{2} \theta_{s}$ (where $H_{s}$ and $\theta_{s}$ are the RMS swell wave height and direction of swell, respectively). This definition leads to singularities when swell propagates perpendicular to radar beam direction $\left(<30^{\circ}\right.$ from perpendicular) and leads to inaccurate swell height estimates. Although our model [see Eq. (5)] does not consider swell propagation direction, its swell estimates (Figs. 9c,d) are better correlated to in situ data than those from the $\cos ^{2} \theta_{s}$ model (Fig. 19). This better performance is present despite the variation in $\theta_{s}$ found at each calibration site (see Table 2 ). The swell mean cross angle, $\theta_{s}$, at sites $\mathrm{O} 2$ and $\mathrm{N} 4$ is $68.2^{\circ}$ and $73.3^{\circ}$, respectively. According to the $\cos ^{2} \theta_{s}$ model these cross angles should create a $65 \%\left[=\cos ^{2}(68.2) /\right.$ $\cos ^{2}(73.3)$ ] increase in $\alpha_{s}$. In our model, any directional effects are included in the calibration factor $\alpha_{s}$, and only a $40 \%$ increase is found $(0.05-0.07$; see Figs. 9c,d). Likely, the wide radar beamwidth $\left(15^{\circ}-\right.$ $\left.35^{\circ}\right)$ at these large radar beam angles $\left(22^{\circ}-55^{\circ}\right)$, combined with a finite spreading parameter of the swell waves, result in significant deviation from the $\cos ^{2} \theta_{s}$ model. Our findings indicate that in the nearshore the swell models of Lipa and Barrick (1980) and Bathgate et al. (2006) overestimate the effect of direction at these swell cross angles, close $\left(<30^{\circ}\right)$ to perpendicular. If this is related to the VHF frequencies of our HF radar or to other parameters is not clear at present and merits further investigation.

\section{b. Inverted bulk wave parameters}

The RMS error between in situ and radar inverted wave height ranges from 0.16 to $0.25 \mathrm{~m}$ with correlation coefficients $r$ ranging from 0.86 to 0.94 . In Table 7, we 
Wind Dir.

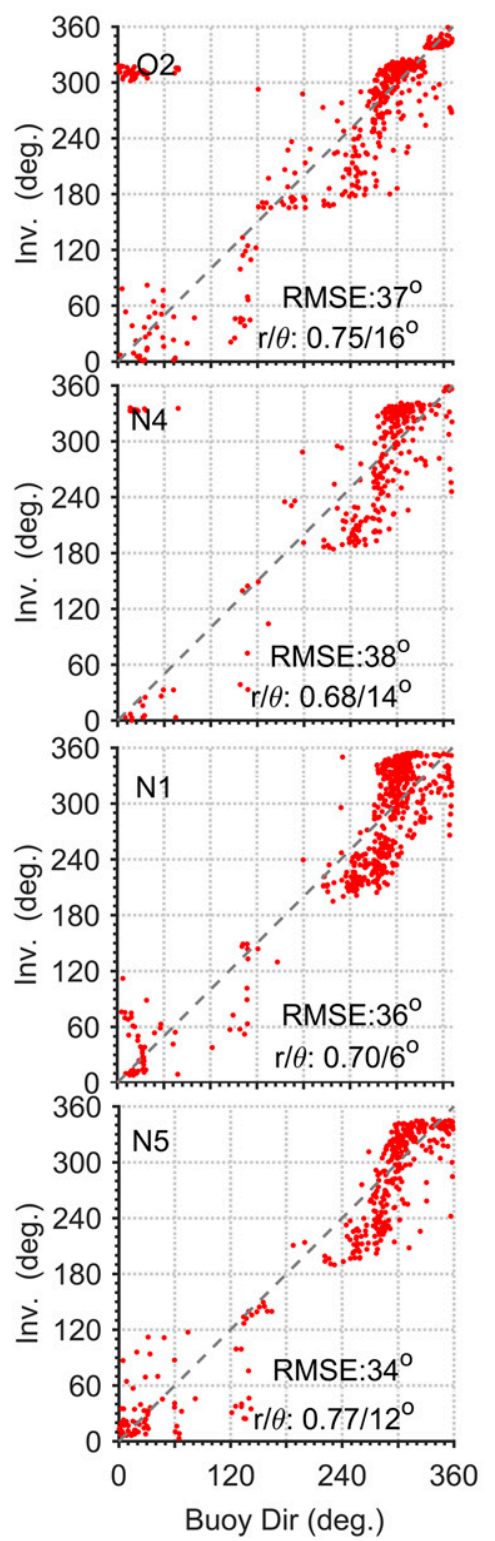

Mean Wave Dir.
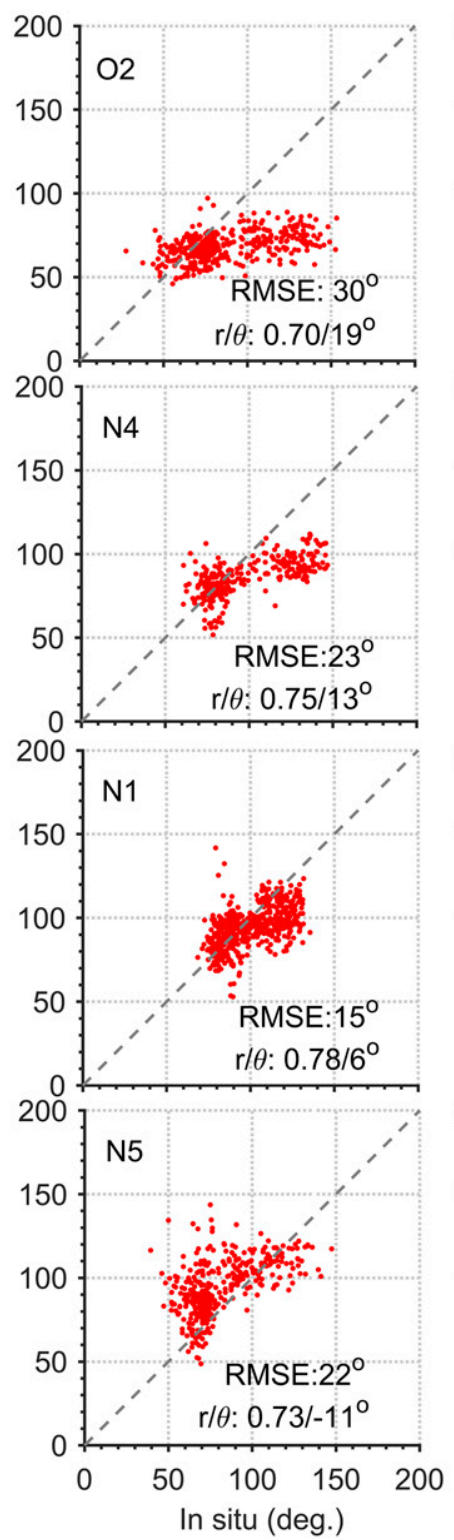

Peak Wave Dir.

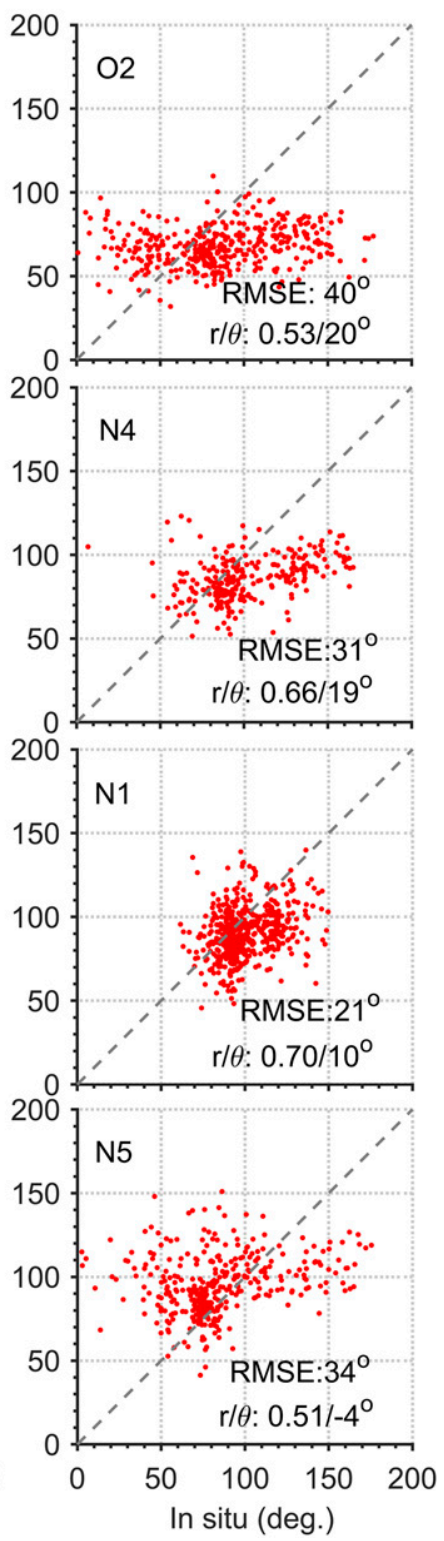

FIG. 14. Scatterplots of inverted vs in situ (left) wind direction, (center) mean wave direction, and (right) peak wave direction at sampling sites O2, N4, N1, and N5. The inverted radar wind direction was determined from the ratio of Bragg peak energies. In situ wind direction was collected from buoy 41025 . Also shown in the panels are complex correlation coefficients $r /$ their corresponding angles $\theta$.

compare our results with those from other studies that have used HF radars of different operating frequency (from 7 to $24.5 \mathrm{MHz}$ ) and different (theoretical and empirical) inversion methods. The lowest wave height RMS error in our study is similar to the lower values reported by those studies while our maximum value is the smallest reported. At the same time our correlation coefficients between inverted wave heights and in situ estimates range from 0.86 to 0.94 . In addition, the errors in wave period estimates for both mean and peak period seem to have the smallest maximum value amongst those reported previously (see Table 7).

In Fig. 20, RMS errors in wave height from each site are plotted against the following parameters: 1) range from the radar site, 2) beam angle, 3) difference in peak energy level between first and second-order peaks, and 4) first-order peak broadening parameter (i.e., half power width). Qualitatively we see that the error tends to increase with range and beam angle. The largest errors in wave heights are found for sites N5 and N6, which 
TABLE 6. Statistical comparison of in situ and inverted estimates of wind direction $\theta_{\text {wind }}$, mean wave direction $\theta_{\text {wm }}$, and peak wave direction $\theta_{\mathrm{wp}}$ for all sites. Values of RMS error $\left(^{\circ}\right)$ and complex correlation coefficient $r$ magnitude and angle of $r\left(^{\circ}\right)$ are listed; $N$ is the number of data points used in the estimations.

\begin{tabular}{|c|c|c|c|c|c|c|c|c|c|c|}
\hline & \multirow[b]{3}{*}{$N$} & \multicolumn{3}{|c|}{$\theta_{\text {wind }}$} & \multicolumn{3}{|c|}{$\theta_{\mathrm{wm}}$} & \multicolumn{3}{|c|}{$\theta_{\mathrm{wp}}$} \\
\hline & & \multirow[b]{2}{*}{ RMS error $\left(^{\circ}\right)$} & \multicolumn{2}{|c|}{ Complex $r$} & \multirow[b]{2}{*}{ RMS error $\left(^{\circ}\right)$} & \multicolumn{2}{|c|}{ Complex $r$} & \multirow[b]{2}{*}{ RMS error $\left(^{\circ}\right)$} & \multicolumn{2}{|c|}{ Complex $r$} \\
\hline & & & Magnitude & Angle $\left(^{\circ}\right)$ & & Magnitude & Angle $\left(^{\circ}\right)$ & & Magnitude & Angle $\left(^{\circ}\right)$ \\
\hline $\mathrm{O} 2$ & 413 & 37 & 0.75 & 16 & 30 & 0.70 & 19 & 40 & 0.53 & 20 \\
\hline N1 & 407 & 36 & 0.70 & 6 & 15 & 0.78 & 6 & 20 & 0.70 & 10 \\
\hline $\mathrm{N} 2$ & 306 & 35 & 0.70 & 4 & 21 & 0.73 & 1 & 27 & 0.61 & 4 \\
\hline N3 & 450 & 39 & 0.68 & 12 & 18 & 0.80 & 9 & 26 & 0.70 & 16 \\
\hline N4 & 214 & 38 & 0.68 & 14 & 23 & 0.75 & 13 & 30 & 0.66 & 19 \\
\hline N5 & 334 & 35 & 0.77 & 12 & 22 & 0.73 & -11 & 33 & 0.51 & -4 \\
\hline N6 & 627 & 32 & 0.75 & 7 & 38 & 0.65 & -33 & 46 & 0.48 & 4 \\
\hline
\end{tabular}

correspond to those with the highest range. Although they also correspond to high beam angles, these are not higher than that for site N2. Sites N5 and N6 are located over Diamond Shoals, an area characterized by shoaling and breaking wave conditions (Kumar et al. 2013) which can cause a broader backscatter signal in the radar (Graber and Heron 1997). The wave height error shows a linear correlation with the broadening parameter (see Fig. 20c) where again sites N5 and N6 indicate a high broadening of the spectrum. It has been shown that the second-order spectra at large radar beam directions $\left(>45^{\circ}\right)$ from the boresight, can be inaccurate due to signal contamination by sidelobe interference (Haus et al. 2010). The calibration sites N4 and $\mathrm{O} 2$ have the lowest radial beam angles $\left(<40^{\circ}\right)$, while all other sites are expected to be more susceptible to sidelobe interference. Despite this issue, radarderived wave spectra performed well at locations with high beam angles (see N1, N2, and N3 in Fig. 20b). Wave height RMS error seems to be reduced with increasing values of first to second-order peak energy ratio (see Fig. 20c). This ratio is inversely correlated with total wave height (not shown in here), which is something not unexpected given that the bigger the waves are the higher is the second-order peak energy. This is in support of the theoretical limitation $0.15<k_{0}$
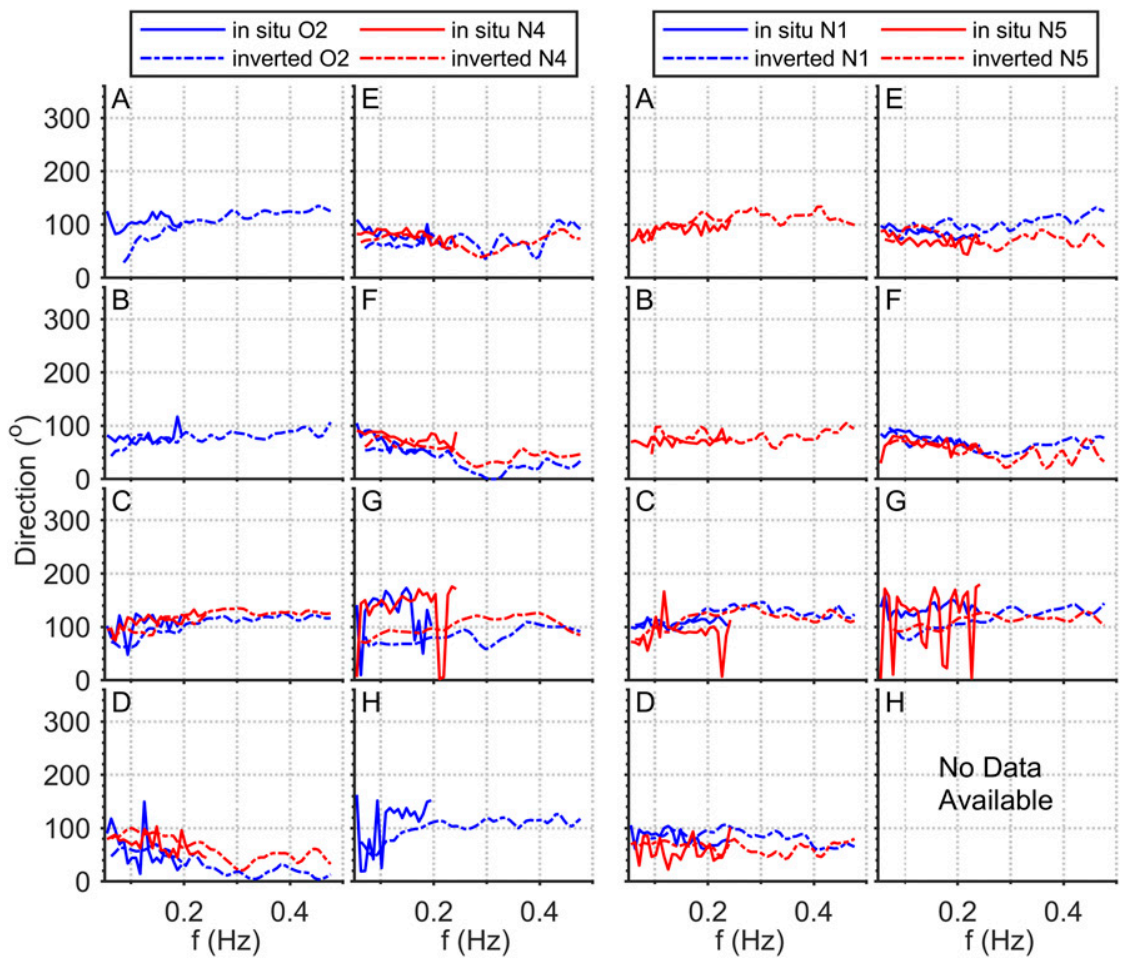

FIG. 15. Examples of inverted $\left[\theta(f)_{\text {inv }}\right]$ and in situ $[\theta(f)]$ wave direction as a function of frequency for the events $(\mathrm{A}-\mathrm{H})$ that are identified in Figs. 3-5. 


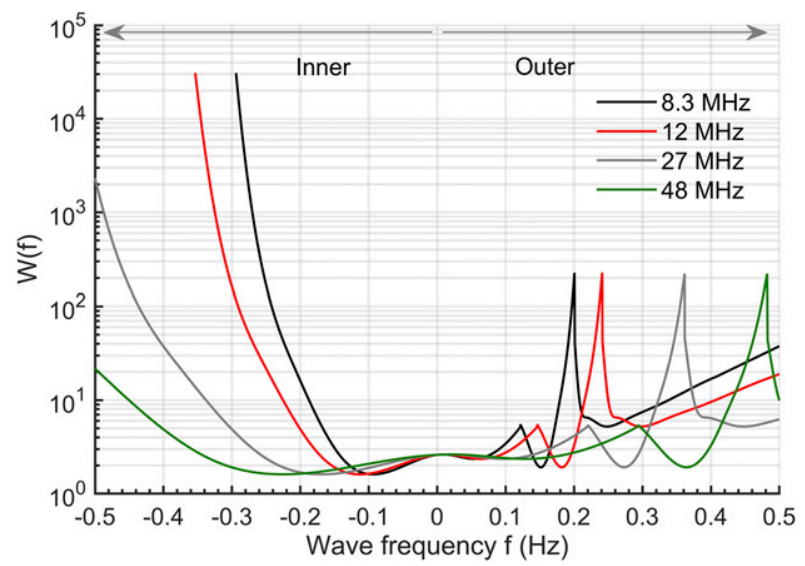

FIG. 16. Diagram of Barrick's deep-water weighting function for selected radar frequencies. The weighting function is plotted in terms of ocean wave frequency, $f=f_{D} \pm f_{B}$. "Inner" denotes second-order sidebands toward the zero Doppler frequency (i.e., left/right of the Bragg peak for positive/negative Doppler frequencies). "Outer" denotes toward $\pm \infty$ Doppler frequency (i.e., right/left of the Bragg peak for positive/negative Doppler frequencies).

$m_{0}<1$ (or $0.42<k_{0} H_{\mathrm{rms}}<2.82$ ) for the application inversion as presented by Barrick (1977b). However, as our data reveal this hard limit is not always applicable as there are cases where the inversion produces good results even under conditions exceeding these limits. We suggest that for practical applications, this ratio could be used as an indicator, perhaps combined with the broadening parameter, of the accuracy of wave height estimates from HF radars.

The peak and mean frequencies (cf. Figs. 11 and 13) and the corresponding peak and mean wave periods are as accurate as those from other wave inversion models (see Table 7). RMS error of mean wave period is $0.79-0.84 \mathrm{~s}$ with correlation coefficient $r$ of $0.8-0.95$. RMS error for peak wave period is $1.38-2.16 \mathrm{~s}$, and $r$ is $0.51-0.84$. These results compare favorably to other studies (Gomez et al. 2015; Wyatt et al. 2006) in which the RMS error of mean wave period is $0.81-2.81 \mathrm{~s}$ with $r$ of $0.52-0.81$ and the peak wave period RMS error is $1.46-4.23 \mathrm{~s}$ with $r$ of $0.33-0.76$ (Gomez et al. 2015).

\section{c. Full spectra inversions}

In individual spectra comparisons (A-H in Fig. 10 and A-G in Fig. 12), during times when wind wave RMS wave height is below $1 \mathrm{~m}$, the spectra are accurately reconstructed (C-H in Fig. 10 and $\mathrm{C}-\mathrm{G}$ in Fig. 12). Furthermore, using a constant value for $\alpha(f)$ allows for the reconstruction of spectrum at frequencies beyond those used in the calibration. However, this is valid only when the weighting function of Barrick (1977b) is applied [see Eq. (3)], which suppresses the harmonic and corner reflections peaks that might exist in the spectrum. Doppler spectra at events A and B are flagged as poor
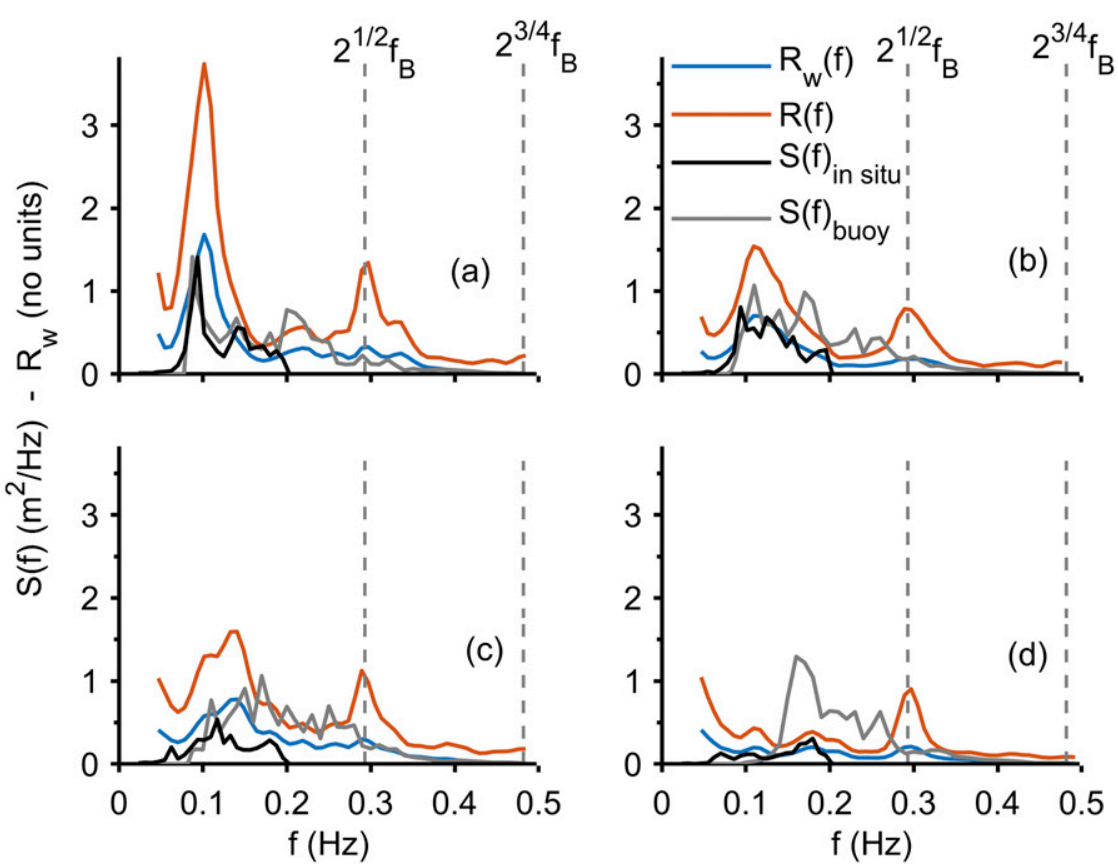

FIG. 17. Examples showing how utilization of the weighting function contributes to reducing the effect of the singular peaks (located at $2^{1 / 2} f_{B}$ and $2^{3 / 4} f_{B}$, where $f_{B}$ is the Bragg frequency) in the normalized second-order Doppler spectra from site O2. Here, $R_{W}$ and $R$ denote weighted and noweighted normalized spectra, respectively, and $S(f)$ denotes in situ wave spectra $\left(\mathrm{m}^{2} \mathrm{~Hz}^{-1}\right)$. 

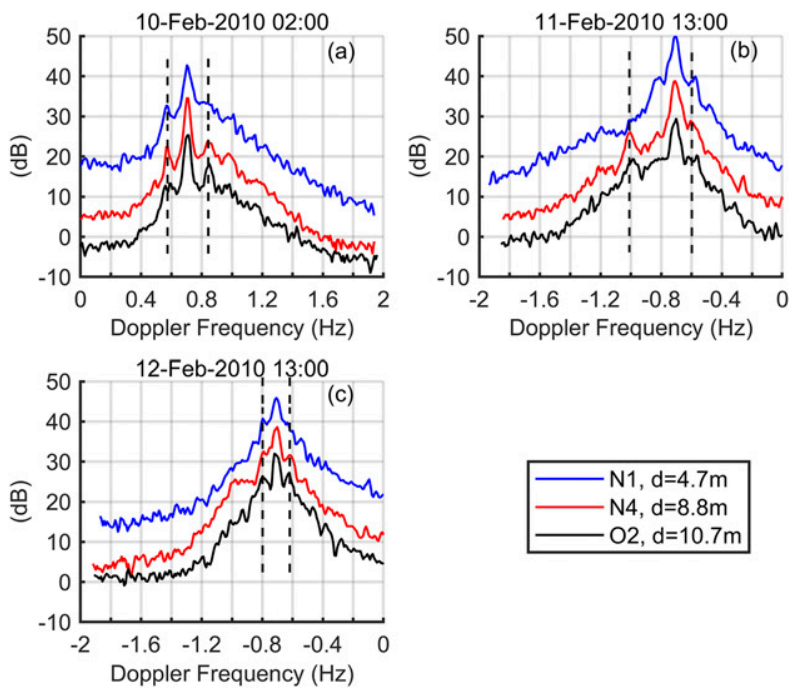

FIG. 18. Doppler spectra from three stations (N1, N4, and O2) corresponding to different mean water depths $(4.7,8.8$, and $10.7 \mathrm{~m}$, respectively) for examples from three different times.

quality due to the Bragg peak not being $5 \mathrm{~dB}$ above the second-order sidebands. Although the higher frequency range (wind seas) of the spectrum is inverted well, the lower frequency part of it is less accurate (see Figs. 10 and 12). This is attributed to the saturation of the Doppler spectrum due to the larger swell wave heights $(>1 \mathrm{~m})$ at these events that contribute to merging of the first and second-order parts of the spectrum. Although this affects the inversion of the wave spectrum at low wave frequencies $(<0.15 \mathrm{~Hz})$ the effect is less severe at higher wave frequencies $(>0.15 \mathrm{~Hz})$; despite this, the total wave height is still accurately reconstructed (Figs. 11 and 13). The inverted spectra estimates extend up to $0.5 \mathrm{~Hz}$. but no in situ spectral estimates are available for these high frequencies; however, the energy roll-off observed in Fig. 12 agrees with the expected theoretical high-frequencsy wave energy roll-off asymptotes (Hasselmann et al. 1973).

\section{d. Wind and wave directions}

Wave direction estimates from the radar seem to be more accurate than those for wind direction (cf. Fig. 14 left and middle panels). However, the wind measurements were from some $29 \mathrm{~km}$ offshore (see Fig. 1) and do not capture the influence of the coastline (see Wu et al. 2017). The wave energy weighted wind direction vectors were well correlated (complex correlation coefficient $r$ values of $0.68-0.77$ ) with a mean angle of $12^{\circ}$. In terms of RMS errors, our error of $32^{\circ}-39^{\circ}$ is similar to those of Wyatt et al. (2006) who used a more complicated theoretical inversion and obtained RMS errors of $23^{\circ}-48^{\circ}$ with linear $r$ values of $0.66-0.89$. For mean wave direction, the hybrid model results in RMS errors of $15^{\circ}-38^{\circ}$ with complex $r$ magnitudes of $0.65-0.8$ and an angle from $-33^{\circ}$ to $9^{\circ}$ (mean of absolute values of $13^{\circ}$ ). This compares well to the study of Wyatt et al. (2009), in which an RMS error of $21^{\circ}$ was found. For peak wave direction, we find an RMS error of $20^{\circ}-46^{\circ}$ with complex $r$ of $0.48-0.7$ and mean complex $r$ direction of $11^{\circ}$, which is smaller than those for mean wave direction.

\section{Conclusions}

We have introduced an empirical hybrid model for VHF radar wave spectra estimates that treats swell and wind waves separately. Using Barrick's (1977b) deep water weighting function results in wind wave coefficients $\left[a(f)_{\mathrm{SNR}}^{+}\right]$that can be assumed to be constant $(=0.255)$ across all ocean wave frequencies. We believe this may be applicable universally but experimental
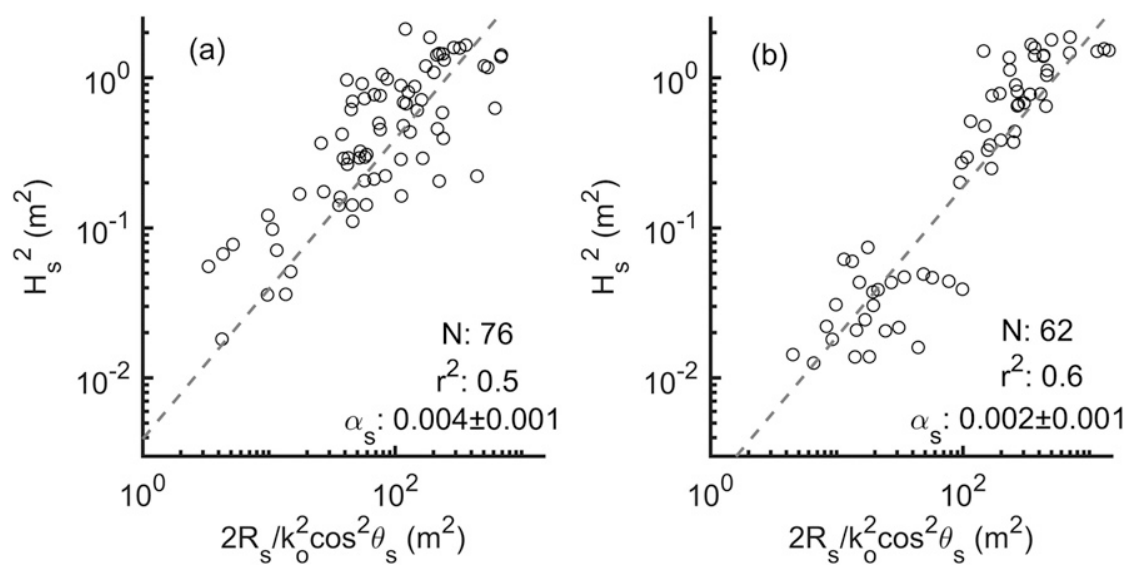

FIG. 19. Regression analysis for the estimation of the swell calibration coefficient using the $\cos ^{2} \theta_{s}$ model, where $\theta_{s}$ is the angle between swell propagation direction and radar beam direction for (a) site $\mathrm{O} 2$ and (b) site N4. 
TABLE 7. Comparison of the performance of the model presented in this study with other theoretical and empirical wave inversion methods reported in the literature and for empirical methods and different radar frequencies. RMS errors and correlation coefficients against in situ measurements are presented.

\begin{tabular}{|c|c|c|c|c|c|c|c|c|}
\hline \multirow[b]{2}{*}{ Inversion type } & \multirow[b]{2}{*}{ Study } & \multirow[b]{2}{*}{$f_{\text {radar }}(\mathrm{MHz})$} & \multicolumn{2}{|c|}{$H_{\mathrm{rms}}(\mathrm{m})$} & \multicolumn{2}{|c|}{$T_{P}(\mathrm{~s})$} & \multicolumn{2}{|l|}{$T_{m}(\mathrm{~s})$} \\
\hline & & & RMS error $(\mathrm{m})$ & $r$ & RMS error (m) & $r$ & RMS error $(m)$ & $r$ \\
\hline \multirow[t]{3}{*}{ Theoretical } & Hisaki (2016) & 24.5 & $0.15-0.86$ & $0.63-0.76$ & - & - & $0.26-0.95$ & $0.69-0.82$ \\
\hline & Wyatt et al. (2006) & $7-10$ & $0.19-0.46$ & $0.55-0.94$ & - & - & $1.27-4.56$ & $0.13-0.81$ \\
\hline & Wyatt et al. (2009) & 16 & $0.28-0.32$ & $0.96-0.97$ & - & - & - & - \\
\hline \multirow[t]{6}{*}{ Empirical } & Chen et al. (2013) & $7.5-25$ & $0.19-1.29$ & $0.45-0.82$ & - & - & - & - \\
\hline & Gomez et al. (2015) & 12 & $0.25-0.48$ & $0.78-0.93$ & $1.46-4.23$ & $0.33-0.76$ & $0.81-2.81$ & $0.52-0.81$ \\
\hline & Middleditch (2013) & 8.34 & $0.36-0.70$ & $0.35-0.51$ & $0.89-2.44$ & $0.3-0.57$ & $0.72-1.26$ & $0.28-0.50$ \\
\hline & Ramos et al. (2009) & 25.4 & $0.14-0.50$ & $0.68-0.95$ & - & - & - & - \\
\hline & Lopez et al. (2016) & 12 & $0.18-0.36$ & $0.88-0.96$ & - & - & - & - \\
\hline & This study & 48 & $0.16-0.25$ & $0.86-0.94$ & $1.38-2.16$ & $0.51-0.84$ & $0.79-0.84$ & $0.80-0.95$ \\
\hline
\end{tabular}

confirmation using radar systems of different frequencies is required. Differences with coefficients found by other studies are attributed to whether Barrick's (1977b) weighting function is utilized, which is something that we strongly recommend to suppress interference by harmonics generated by the EM wave and ocean wave interactions.

A separate coefficient Eq. (5) for swell is needed that does not correlate well with $\cos ^{2} \theta_{s}$ at $\pm 30^{\circ}$ from perpendicular. After calibration, this hybrid model has the ability to accurately reconstruct wave spectra even when swell is propagating close to perpendicular to the radar. Application of the swell module requires that swell propagation direction is constrained by site location, and therefore can be assumed roughly constant. Although this model requires calibration for locations that have different cross angles $\left(\theta_{s}\right.$, i.e., the angle between the radar beam direction and swell propagation direction), it shows a significant improvement from theoretical $\cos ^{2} \theta_{s}$ models (Lipa and Barrick 1980; Bathgate et al. 2006) of swell (cf. Fig. 19 with Fig. 9, lower panels) beam direction.

Both swell and wind wave spectra are reconstructed at similar levels of accuracy to previous studies (e.g., Wyatt et al. 2009; Gomez et al. 2015; Lopez et al. 2016), and the radar estimated wave spectra show similar trends at high frequencies $(f>0.2 \mathrm{~Hz})$ that closely align to $f^{-4}$ and $f^{-5}$ wave energy roll-off (see Figs. 10 and 12). Note that in this study $(48 \mathrm{MHz})$, accurate wave spectra reconstruction is limited to high frequencies when high energy of swell ( $>1 \mathrm{~m}$ ) is present, although total RMS wave height is still accurately estimated.
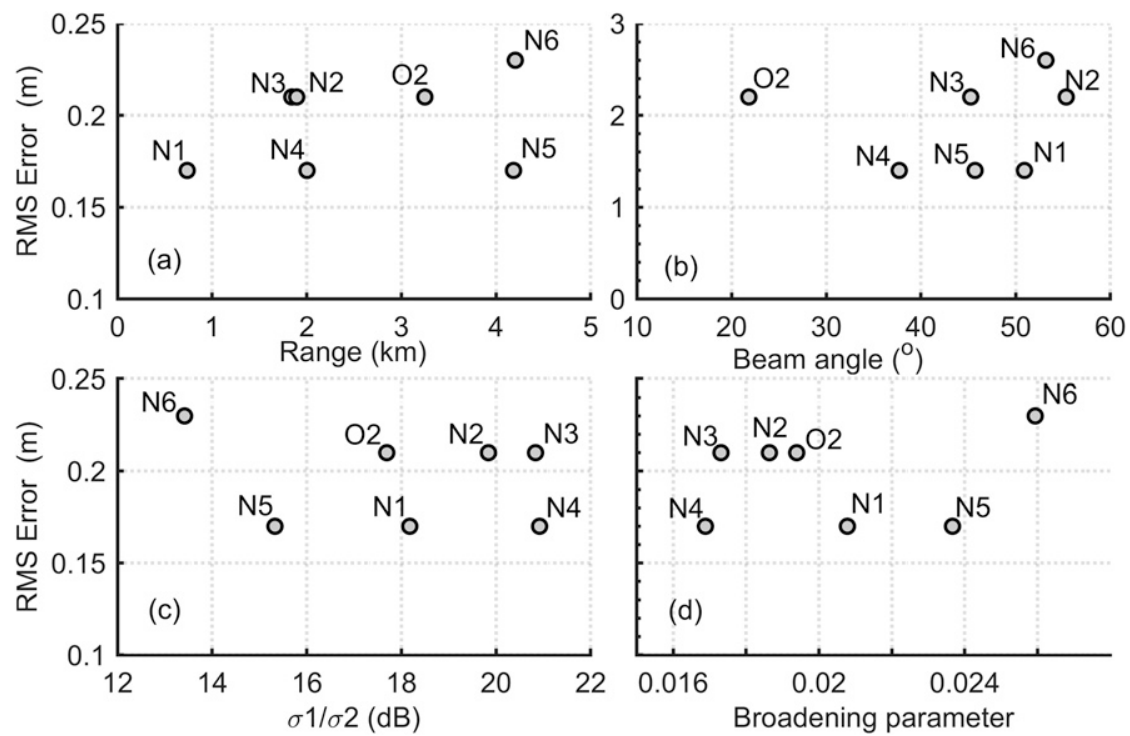

FIG. 20. Scatterplots of HF radar parameters and wave height RMS error at all sampling sites vs (a) range $(\mathrm{km})$, (b) beam angle (degrees from boresight), (c) ratio of first- to second-order peak energies $(\mathrm{dB})$, and $(\mathrm{d})$ broadening parameter. 
The hybrid method presented here is characterized by its simplicity, requiring a single calibration coefficient for the wind wave spectrum and calibration and frequency width coefficients for swell. However, there is some effect of direction, resulting in the different swell calibration constants between calibration sites $\mathrm{O} 2$ and N4. The lack of a radar inversion swell method for swell propagating at large cross angles results in the requirement of this model to be calibrated separately at locations where the cross angle of swell changes significantly. A more detailed analysis, from both a theoretical and an experimental basis, of swell's effect on the radar signal when its propagation direction is close to perpendicular is needed for reconstructing swell wave spectra from radar Doppler spectra at uncalibrated locations.

The MATLAB software scripts for implementation of the inversion model presented in this paper [the Wave Radar Inversion Code (WaveRIC)] are available online (Cahl et al. 2019).

Acknowledgments. The experimental work was funded by the Carolinas Coastal Processes Project, a cooperative study supported by the U.S. Geological Survey. Additional support during data analysis and preparation of this paper was provided by the Southeast Coastal Observing Regional Association (SECOORA) pursuant to NOAA Award NA16NOS0120028. The first author (Z. Alattabi) was supported by a fellowship from the Higher Committee for Education Development (HCED) in Iraq. Paper preparation and finalization took place while G. Voulgaris was serving at the U.S. National Science Foundation. Any opinions, findings, and conclusions or recommendations expressed in here are those of the authors and do not necessarily reflect the views of any of the funding organizations.

\section{REFERENCES}

Armstrong, B. N., and Coauthors, 2013: Carolinas Coastal Change Processes Project data report for nearshore observations at Cape Hatteras, North Carolina. USGS Open-File Rep. 20121219, https://doi.org/10.3133/ofr20121219.

Barrick, D. E., 1971: Theory of HF and VHF propagation across the rough sea, 1 , The effective surface impedance for a slightly rough highly conducting medium at grazing incidence. Radio Sci., 6, 517-526, https://doi.org/10.1029/RS006i005p00517.

_- 1977a: The ocean waveheight nondirectional spectrum from inversion of the HF sea-echo Doppler spectrum. $R e$ mote Sens. Environ., 6, 201-227, https://doi.org/10.1016/ 0034-4257(77)90004-9.

— 1977b: Extraction of wave parameters from measured HF radar sea-echo Doppler spectra. Radio Sci., 12, 415-424, https://doi.org/10.1029/RS012i003p00415.

— ity waves on the ocean's surface. Part II: Interpretation and applications. J. Phys. Oceanogr., 7, 11-21, https://doi.org/ 10.1175/1520-0485(1977)007<0011:OTNTFG > 2.0.CO;2.

Bathgate, J. S., M. L. Heron, and A. Prytz, 2006: A method of swellwave parameter extraction from HF ocean surface radar spectra. IEEE J. Oceanic Eng., 31, 812-818, https://doi.org/ 10.1109/JOE.2006.886237.

Bishop, C. T., and M. A. Donelan, 1987: Measuring waves with pressure transducers. Coastal Eng., 11, 309-328, https:// doi.org/10.1016/0378-3839(87)90031-7.

Broche, P., P. Forget, J. De Maistre, J. Devenon, and M. Crochet, 1987: VHF radar for ocean surface current and sea state remote sensing. Radio Sci., 22, 69-75, https://doi.org/10.1029/ RS022i001p00069.

Cahl, D., G. Voulgaris, and Z. Alattabi, 2019: Wave Radar Inversion Code (WaveRIC) V1.0.1, https://doi.org/10.5281/zenodo.2643696.

Chen, Z., C. Zezong, J. Yanni, F. Lingang, and Z. Gengfei, 2013: Exploration and validation of wave-height measurement using multifrequency HF radar. J. Atmos. Oceanic Technol., 30, 2189-2202, https://doi.org/10.1175/JTECH-D-12-00178.1.

Collard, F., F. Ardhuin, and B. Chapron, 2005: Extraction of coastal ocean wave fields from SAR images. IEEE J. Oceanic Eng., 30, 526-533, https://doi.org/10.1109/JOE.2005.857503.

Crombie, D. D., 1955: Doppler spectrum of sea echo at $13.56 \mathrm{Mc} . / \mathrm{s}$. Nature, 175, 681, https://doi.org/10.1038/175681a0.

Fernandez, D. M., H. C. Graber, J. D. Paduan, and D. E. Barrick, 1997: Mapping wind direction with HF radar. Oceanography, 10, 93-95, https://doi.org/10.5670/oceanog.1997.33.

Forget, P., P. Broche, J. De Maistre, and A. Fontanel, 1981: Sea state frequency features observed by ground wave HF Doppler radar. Radio Sci., 16, 917-925, https://doi.org/10.1029/ RS016i005p00917.

Gill, E. W., 1990: An algorithm for the extraction of ocean wave parameters from wide beam $\mathrm{HF}$ radar (CODAR) backscatter. Ph.D dissertation, Memorial University of Newfoundland, $267 \mathrm{pp}$.

- and J. Walsh, 2001: High-frequency bistatic cross sections of the ocean surface. Radio Sci., 36, 1459-1475, https://doi.org/ 10.1029/2000RS002525.

Gomez, R., T. Helzel, L. Wyatt, G. Lopez, D. Conley, N. Thomas, S. Smet, and G. Sicot, 2015: Estimation of wave parameters from HF radar using different methodologies and compared with wave buoy measurements at the Wave Hub. OCEANS 2015-Genova, Genoa, Italy, IEEE, https://doi.org/10.1109/ OCEANS-Genova.2015.7271477.

Graber, H. C., and M. L. Heron, 1997: Wave height measurements from HF radar. Oceanography, 10, 90-92, https://doi.org/ 10.5670/oceanog.1997.32.

Gurgel, K.-W., G. Antonischki, H. H. Essen, and T. Schlick, 1999: Wellen Radar (WERA): A new ground-wave HF radar for ocean remote sensing. Coastal Eng., 37, 219-234, https:// doi.org/10.1016/S0378-3839(99)00027-7.

—, H. H. Essen, and T. Schlick, 2006: An empirical method to derive ocean waves from second-order Bragg scattering: prospects and limitations. IEEE J. Oceanic Eng., 31, 804-811, https://doi.org/10.1109/JOE.2006.886225.

Guymer, T. H., 1990: Measuring ocean waves with altimeters and synthetic aperture radars. Microwave Remote Sensing for Oceanographic and Marine Weather-Forecast Models, R. A. Vaughan, Ed., Springer, 65-97, https://doi.org/10.1007/978-94-009-0509-2_4.

Hanson, J. L., and O. M. Phillips, 2001: Automated analysis of ocean surface directional wave spectra. J. Atmos. Oceanic Technol., 18, 277-293, https://doi.org/10.1175/ 1520-0426(2001)018<0277:AAOOSD>2.0.CO;2. 
Hasselmann, K., 1971: Determination of ocean wave spectra from Doppler radio return from the sea surface. Nat. Phys. Sci., 229, 16, https://doi.org/10.1038/physci229016a0.

— , and Coauthors, 1973: Measurements of wind-wave growth and swell decay during the Joint North Sea Wave Project (JONSWAP). Hydraulic Engineering Rep. 8-12, 93 pp., http://resolver.tudelft.nl/ uuid:f204e188-13b9-49d8-a6dc-4fb7c20562fc.

Haus, B. K., L. K. Shay, P. A. Work, G. Voulgaris, R. J. Ramos, and J. Martinez-Pedraja, 2010: Wind speed dependence of singlesite wave-height retrievals from high-frequency radars. J. Atmos. Oceanic Technol., 27, 1381-1394, https:// doi.org/10.1175/2010JTECHO730.1.

Herbers, T., S. Elgar, and R. Guza, 1999: Directional spreading of waves in the nearshore. J. Geophys. Res., 104, 7683-7693, https://doi.org/10.1029/1998JC900092.

Heron, S., and M. Heron, 1998: A comparison of algorithms for extracting significant wave height from HF radar ocean backscatter spectra. J. Atmos. Oceanic Technol., 15, 1157-1163, https://doi.org/10.1175/1520-0426(1998)015<1157: ACOAFE $>2.0 . \mathrm{CO} ; 2$.

Heron, M., P. Dexter, and B. McGann, 1985: Parameters of the air-sea interface by high-frequency ground-wave Doppler radar. Mar. Freshw. Res., 36, 655-670, https://doi.org/ 10.1071/MF9850655.

Hildebrand, P. H., and R. Sekhon, 1974: Objective determination of the noise level in Doppler spectra. J. Appl. Meteor., 13, 808-811, https://doi.org/10.1175/1520-0450(1974)013<0808: ODOTNL $>2.0 . \mathrm{CO} ; 2$.

Hisaki, Y., 1996: Nonlinear inversion of the integral equation to estimate ocean wave spectra from HF radar. Radio Sci., 31, 25-39, https://doi.org/10.1029/95RS02439.

_ 2016: Ocean wave parameters and spectrum estimated from single and dual high-frequency radar systems. Ocean Dyn., 66, 1065-1085, https://doi.org/10.1007/s10236-016-0978-3.

Howell, R., and J. Walsh, 1993: Measurement of ocean wave spectra using narrow-beam HE radar. IEEE J. Oceanic Eng., 18, 296-305, https://doi.org/10.1109/JOE.1993.236368.

Jackson, F. C., 1981: An analysis of short pulse and dual frequency radar techniques for measuring ocean wave spectra from satellites. Radio Sci., 16, 1385-1400, https://doi.org/ 10.1029/RS016i006p01385.

Kumar, N., G. Voulgaris, J. H. List, and J. C. Warner, 2013: Alongshore momentum balance analysis on a cuspate foreland. J. Geophys. Res. Oceans, 118, 5280-5295, https://doi.org/ 10.1002/jgrc.20358.

— D. L. Cahl, S. C. Crosby, and G. Voulgaris, 2017: Bulk versus spectral wave parameters: Implications on stokes drift estimates, regional wave modeling, and HF radars applications. J. Phys. Oceanogr., 47, 1413-1431, https://doi.org/10.1175/ JPO-D-16-0203.1.

Kundu, P. K., 1976: Ekman veering observed near the ocean bottom. J. Phys. Oceanogr., 6, 238-242, https://doi.org/10.1175/ 1520-0485(1976)006<0238:EVONTO >2.0.CO;2.

Lipa, B. J., 1977: Derivation of directional ocean-wave spectra by integral inversion of second-order radar echoes. Radio Sci., 12, 425-434, https://doi.org/10.1029/RS012i003p00425.

_, 1978 : Inversion of second-order radar echoes from the sea. J. Geophys. Res, 83, 959-962, https://doi.org/10.1029/ JC083iC02p00959.

, and D. E. Barrick, 1980: Methods for the extraction of longperiod ocean wave parameters from narrow beam HF radar sea echo. Radio Sci., 15, 843-853, https://doi.org/10.1029/ RS015i004p00843.
- - —, and J. W. Maresca, 1981: HF radar measurements of long ocean waves. J. Geophys. Res., 86, 4089-4102, https:// doi.org/10.1029/JC086iC05p04089.

— B. Byden, D. Barrick, and J. Kohut, 2008: HF radar sea-echo from shallow water. Sensors, 8, 4611-4635, https://doi.org/ 10.3390/s8084611.

List, J. H., J. C. Warner, E. R. Thieler, K. Haas, G. Voulgaris, J. E. McNinch, and K. L. Brodie, 2011: A nearshore processes field experiment at Cape Hatteras, North Carolina, USA. The Proceedings of the Coastal Sediments 2011, J. D. Rosati, P. Wang, and T. M. Roberts, Eds., World Scientific, 2144 2157, https://doi.org/10.1142/9789814355537_0161.

Long, A., and D. Trizna, 1973: Mapping of North Atlantic winds by $\mathrm{HF}$ radar sea backscatter interpretation. IEEE Trans. Antennas Propag., 21, 680-685, https://doi.org/10.1109/ TAP.1973.1140557.

Longuet-Higgins, M. S., 1963: The effect of non-linearities on statistical distributions in the theory of sea waves. J. Fluid Mech., 17, 459-480, https://doi.org/10.1017/S0022112063001452.

Lopez, G., D. C. Conley, and D. Greaves, 2016: Calibration, validation, and analysis of an empirical algorithm for the retrieval of wave spectra from HF radar sea echo. J. Atmos. Oceanic Technol., 33, 245-261, https://doi.org/ 10.1175/JTECH-D-15-0159.1.

Maresca, J. W., Jr., and T. M. Georges, 1980: Measuring RMS wave height and the scalar ocean wave spectrum with HF skywave radar. J. Geophys. Res. 85, 2759-2771, https://doi.org/10.1029/ JC085iC05p02759.

Middleditch, A., 2013: Spatiotemporal spectral averaging of highfrequency radar wave data. ACORN Rep. 2013-3, 45 pp., http://imos.org.au/fileadmin/user_upload/shared/ACORN/ reports/2013-3-Spatiotemporal-Spectral-Averaging-of-HighFrequency-Radar-Wave-Data.pdf.

Molcard, A., P. M. Poulain, P. Forget, A. Griffa, Y. Barbin, J. Gaggelli, J. C. De Maistre, and M. Rixen, 2009: Comparison between VHF radar observations and data from drifter clusters in the Gulf of La Spezia (Mediterranean Sea). J. Mar. Syst., 78, S79-S89, https://doi.org/10.1016/ j.jmarsys.2009.01.012.

Paduan, J. D., and L. K. Rosenfeld, 1996: Remotely sensed surface currents in Monterey Bay from shore-based HF radar (Coastal Ocean Dynamics Application Radar). J. Geophys. Res., 101, 20 669-20 686, https://doi.org/10.1029/96JC01663.

—, and I. Shulman, 2004: HF radar data assimilation in the Monterey Bay area. J. Geophys. Res., 109, C07S09, https:// doi.org/10.1029/2003JC001949.

— of ocean surface currents. Annu. Rev. Mar. Sci., 5, 115-136, https://doi.org/10.1146/annurev-marine-121211-172315.

Ramos, R. J., H. C. Graber, and B. K. Haus, 2009: Observation of wave energy evolution in coastal areas using HF radar. J. Atmos. Oceanic Technol., 26, 1891-1909, https://doi.org/ 10.1175/2009JTECHO631.1.

Shay, L. K., T. M. Cook, H. Peters, A. J. Mariano, R. Weisberg, P. E. An, A. Soloviev, and M. Luther, 2002: Very high-frequency radar mapping of surface currents. IEEE J. Oceanic Eng., 27, 155169, https://doi.org/10.1109/JOE.2002.1002470.

Shrira, V. I., D. V. Ivonin, P. Broche, and J. C. Maistre, 2001: On remote sensing of vertical shear of ocean surface currents by means of a Single-frequency VHF radar. Geophys. Res. Lett., 28, 3955-3958, https://doi.org/10.1029/2001GL013387.

Stewart, R. H., 1971: September. Higher order scattering of radio waves from the sea. 1971 Antennas and Propagation Society 
International Symposium, Los Angeles, CA, IEEE, 190-193, https://doi.org/10.1109/APS.1971.1150935.

Voulgaris, G., N. Kumar, K.-W. Gurgel, J. C. Warner, and J. H. List, 2011: 2-D inner-shelf current observations from a single VHF WEllen RAdar (WERA) station. 2011 IEEE/OES 10th Current, Waves and Turbulence Measurements, Monterey, CA, IEEE, 57-65, https://doi.org/10.1109/CWTM.2011.5759525.

Wang, W., P. Forget, and C. Guan, 2016: Inversion and assessment of swell waveheights from HF radar spectra in the Iroise Sea. Ocean Dyn., 66, 527-538, https://doi.org/10.1007/ s10236-016-0941-3.

Waters, J., L. R. Wyatt, J. Wolf, and A. Hines, 2013: Data assimilation of partitioned HF radar wave data into Wavewatch III. Ocean Modell., 72, 17-31, https://doi.org/10.1016/j.ocemod.2013.07.003.

Weber, B. L., and D. E. Barrick, 1977: On the nonlinear theory for gravity waves on the ocean's surface. Part I: Derivations. J. Phys. Oceanogr., 7, 3-10, https://doi.org/10.1175/ 1520-0485(1977)007<0003:OTNTFG > 2.0.CO;2.

Welch, P., 1967: The use of fast Fourier transform for the estimation of power spectra: a method based on time averaging over short, modified periodograms. IEEE Trans. Audio Electroacoust., 15, 70-73, https://doi.org/10.1109/TAU.1967.1161901.

WMO, 1998: Guide to wave analysis and forecasting. 2nd ed. WMO Rep. WMO-702, 159 pp., https://library.wmo.int/ doc_num.php?explnum_id $=3110$.

Work, P. A., 2008: Nearshore directional wave measurements by surface-following buoy and acoustic Doppler current profiler. Ocean Eng., 35, 727-737, https://doi.org/10.1016/ j.oceaneng.2008.02.005.

Wu, X., G. Voulgaris, and N. Kumar, 2017: Parameterization of synoptic weather systems in the South Atlantic Bight for modeling applications. Ocean Dyn., 67, 1231-1249, https:// doi.org/10.1007/s10236-017-1084-x.

Wyatt, L. R., 1990: A relaxation method for integral inversion applied to HF radar measurement of the ocean wave directional spectrum. Int. J. Remote Sens., 11, 1481-1494, https:// doi.org/10.1080/01431169008955106.

_ 2002: An evaluation of wave parameters measured using a single HF radar system. Can. J. Rem. Sens., 28, 205-218, https://doi.org/10.5589/m02-018.

—_, G. Liakhovetski, H. C. Graber, and B. K. Haus, 2005: Factors affecting the accuracy of Showex HF radar wave measurements. J. Atmos. Oceanic Technol., 22, 847-859, https://doi.org/10.1175/JTECH1728.1.

— J. J. Green, A. Middleditch, M. D. Moorhead, J. Howarth, M. Holt, and S. Keogh, 2006: Operational wave, current, and wind measurements with the Pisces HF radar. IEEE J. Oceanic Eng., 31, 819-834, https://doi.org/10.1109/JOE.2006.888378.

,-- , and $\_, 2009$ : Signal sampling impacts on HF radar wave measurement. J. Atmos. Oceanic Technol., 26, 793-805, https://doi.org/10.1175/2008JTECHO614.1.

Young, I., 1995: The determination of confidence limits associated with estimates of the spectral peak frequency. Ocean Eng., 22, 669-686, https://doi.org/10.1016/0029-8018(95)00002-3.

__ and L. Verhagen, 1996: The growth of fetch limited waves in water of finite depth. Part 1 . Total energy and peak frequency. Coastal Eng., 29, 47-78, https://doi.org/10.1016/ S0378-3839(96)00006-3.

Zhang, J., and E. W. Gill, 2006: Extraction of ocean wave spectra from simulated noisy bistatic high-frequency radar data. IEEE J. Oceanic Eng., 31, 779-796, https://doi.org/ 10.1109/JOE.2006.886201. 